\title{
La necesidad del diálogo entre la justicia constitucional y el arbitraje internacional de inversiones*
}

\author{
AndrÉs Cervantes VAlarezo ${ }^{1}$
}

\section{RESUMEN}

Este artículo pone de manifiesto la tensión existente entre el arbitraje internacional de inversión, el derecho internacional de los derechos humanos y el derecho constitucional. Luego de exponer las principales objeciones frente al arbitraje internacional de inversión como la falta de transparencia, seguridad jurídica, legitimidad y responsabilización de los árbitros, se analiza la novedosa Sentencia c-252/2019 de la Corte Constitucional de Colombia y se analiza el rol virtuoso que debe ejercer la justicia constitucional respecto del arbitraje de inversión. Un razonamiento y una argumentación que tome en consideración los intereses y derechos del inversionista extranjero pueden contribuir a paliar los déficits estructurales del arbitraje de inversión y fortalecerlo. Desde la perspectiva del Estado receptor de la inversión, puede prevenir demandas internacionales o coadyuvar a eximirle de responsabilidad. Se plantea, entonces, la necesidad de un diálogo reflexivo y amplio entre estas dos formas de adjudicación de derecho público.

Palabras clave: justicia constitucional, arbitraje de inversión, diálogo reflexivo, covid-19, prevención, margen de apreciación nacional, proporcionalidad, pandemia.

1 Abogado. Máster en Ciencias Jurídicas Avanzadas y doctor en Derecho por la Universitat Pompeu Fabra (UPF) de Barcelona y máster en Derecho Constitucional por la Universitat de Valencia. Docenteinvestigador en la UPF y profesor de derecho constitucional en la Universidad de Especialidades Espíritu Santo (UEES) en Ecuador. Correo electrónico: andres.cervantes@upf.edu. ORCID: https:// orcid.org/0000-0003-4644-3977

* DOI: https://doi.org/10.18601/01236458.n56.06 


\section{ABSTRACT}

The article highlights the tension between international investment arbitration, international human rights law, and constitutional law. After analyzing the main objections to investment treaty arbitration such as the lack of transparency, legal certainty, legitimacy and accountability of the arbitrators, the paper examines the novel judgment c-252/2019 of the Constitutional Court of Colombia which is an example of the virtuous role to be exercised by constitutional justice regarding investment arbitration. When constitutional justice incorporates in its reasoning and argumentation the diversity of interests and rights both foreign investor and the society it can contribute to alleviate the structural deficits of investment arbitration while contributing on strengthen it. From the perspective of the host State, it can prevent international lawsuits or to argue an exemption of international liability. The central idea is to defend the need to develop a serious and reflexive dialogue between these authorities of public law adjudication.

Keywords: Constitutional Justice, investment arbitration, reflexive dialogue, covid-19, prevention, national margin of appreciation, proportionality, pandemic.

\section{INTRODUCCIÓN}

El arbitraje internacional de inversiones (AII) es el foro por excelencia y consolidado para dirimir las disputas entre los inversores extranjeros y el Estado receptor de la inversión extranjera (IE). El primer tratado bilateral de inversión (TBI) o acuerdos de promoción y protección recíproca de inversiones (APPRI) fue celebrado entre Alemania y Pakistán en 1959 y, hoy en día, existen más de 3284 tratados internacionales de este tipo y al menos 1023 casos (ONU, 2020, pp. 22-23), lo que da cuenta de su importancia en el derecho internacional. Esta especie de tratados internacionales implicó la teorización de una nueva rama del derecho económico internacional, el denominado derecho internacional de las inversiones (Cervantes, 2017).

La idea fundamental de los APPRI es sencilla, pero poderosa: dado que es necesario solucionar las controversias surgidas entre inversionistas extranjeros y estados receptores de la inversión de forma pacífica y en un foro neutral ajeno de posibles injerencias en los sistemas judiciales nacionales, los inversionistas tienen derecho a someter aquellas controversias ante un tribunal de arbitraje internacional, donde el derecho aplicable al fondo del asunto es el APPRI. A tal efecto, aquel reconoce determinadas garantías al inversionista por parte del Estado receptor de la inversión: el trato justo y equitativo, la prohibición de discriminación, la obligación de prestar seguridades plenas a la inversión, la prohibición de confiscación y la obligación de tratar al inversionista del mismo modo que se trata a otros nacionales o extranjeros con los que el Estado hubiese celebrado otro APPRI en términos más favorables (Ferreres, 2015). 
Sin embargo, la literatura especializada y la casuística arbitral demuestran que en este tipo de controversias no se sustancian cuestiones de puro derecho privado, sino que el AII puede tratar cuestiones relacionadas a derechos humanos, especialmente, algunas que inciden con los denominados derechos económicos, sociales, culturales y ambientales, además de la propia capacidad regulatoria del Estado receptor de la inversión. En ese sentido, es del todo pacífico afirmar, hoy en día, que el AIl es "un mecanismo descentralizado de ejercicio de poder público con sede internacional" (Ureña y Prada-Uribe, 2019). Tomando en cuenta los déficits de legitimidad, transparencia, seguridad jurídica, de responsabilización y otros problemas estructurales del AII, se producen tensiones respecto de este método de solución de controversias con el derecho constitucional y con el derecho internacional de los derechos humanos (DIDH).

El objetivo del presente artículo es analizar las formas de interacción entre el AII y el derecho constitucional y reflexionar sobre el rol positivo que puede ejercer la justicia constitucional en la consolidación del AII para paliar los déficits estructurales de este. A tal efecto, se pondrá énfasis en la Sentencia c-252/2019 de la Corte Constitucional de Colombia (CCC), en la que la magistratura constitucional, ejerciendo el control de constitucionalidad previo de tratados internacionales, condicionó la firma de un TBI entre Colombia y Francia a que el presidente de la República pacte una declaración interpretativa que especifique el significado y alcance de términos vagos y/o ambiguos del tratado con el propósito de garantizar la seguridad jurídica.

Por supuesto, estas páginas se inspiran en una pregunta fundamental: con la mira puesta en el 2030, ¿qué interés puede tener analizar las tensiones entre el derecho constitucional y el arbitraje de inversiones?, ¿por qué es necesario reflexionar sobre el rol de los guardianes de la constitución y los guardianes de los APPRI? No se puede pasar por alto que el 2020 y los años que vendrán (esperemos no demasiados) estarán marcados por el azote de la pandemia del covid-19. Una pandemia de estas características obligó a decenas de Estados a adoptar estados de excepción o legislación de urgencia que, fundamentadas en la seguridad pública, implican daños para los inversionistas extranjeros.

Adicionalmente, en virtud del principio de responsabilidad unitaria del Estado ${ }^{2}$, las propias decisiones de los tribunales constitucionales pueden ser consideradas como fuente de ilícito internacional en el AI (Schill, 2017). Por estos motivos, resulta más importante que nunca tender puentes de diálogo entre el derecho internacional de las inversiones, el derecho constitucional y el DIDH.

2 El artículo 1 de los Artículos sobre Responsabilidad del Estado por Hechos Internacionalmente ilícitos (Asamblea General onU, 2001) indica que: "Todo hecho internacionalmente ilícito del Estado genera su responsabilidad internacional". Por su parte, el artículo 4.1 del mismo instrumento señala: "Se considerará hecho del Estado según el derecho internacional el comportamiento de todo órgano del Estado ya sea que ejerza funciones legislativas, ejecutivas, judiciales o de otra índole, cualquiera que sea su posición en la organización del Estado y tanto si pertenece al gobierno central como a una división territorial del Estado". 
La tesis que defenderé a lo largo de estas páginas es la siguiente: los tribunales constitucionales pueden y deben ejercer un rol preventivo respecto del arbitraje de inversión en cinco (5) momentos: 1. El control previo y abstracto de los tratados internacionales; 2 . Cuando se producen casos de jurisdicción concurrente; 3 . Cuando se controla la ejecución de un laudo arbitral internacional no-CIADI; 4. Cuando se realiza el control de constitucionalidad de la legislación o regulación que implementa un APPRI y 5 . Al momento de realizar un control concreto de los estados de excepción y de las medidas adoptadas durante la pandemia del covid-19.

Pienso, en definitiva, que los tribunales constitucionales deben incorporar en su razonamiento jurídico no solamente normas del DIDH, que es una tendencia común, a efectos de prevenir la responsabilidad internacional del Estado en materia de DDHH, sino también incorporar en sus decisiones un razonamiento basado en el derecho internacional de las inversiones. Aquello sería demostrativo de que la justicia constitucional ha analizado seriamente todos los intereses y derechos en juego y compelería a los paneles de arbitraje internacional a incorporar en su razonamiento jurídico y argumentación las normas de DIDH y las normas de derecho internacional público sobre exención de responsabilidad estatal. En pocas palabras, sentaría las bases para un diálogo basado en el equilibrio reflexivo amplio. Ello implica dejar de pensar en el AII como un régimen jurídico autocontenido (UNCTAD, 2014) y entenderlo como un sistema jurídico permeable a otras fuentes del derecho internacional (Simma, 2011).

Para este fin, el artículo se divide en tres apartados. En el primero, se realiza una breve introducción a las principales críticas del régimen de arbitraje internacional de inversión para dimensionar los aspectos procedimentales del problema. En el segundo apartado se analiza cómo estos déficits funcionales han repercutido desfavorablemente al régimen del arbitraje de inversión y se muestra una tendencia constitucional y jurisprudencial en América Latina al rechazo de este mecanismo de solución de disputas. Además, se pone de manifiesto que una de las principales objeciones al régimen es la limitación de la potestad regulatoria de los Estados y la ausencia del DIDH en el razonamiento arbitral. En el tercer apartado, luego de haber determinado las carencias funcionales y de legitimidad del régimen, se analizan los mecanismos institucionales para fomentar el diálogo entre la justicia constitucional y el arbitraje de inversión. Finalmente, se presenta una conclusión general.

\section{EL ARBITRAJE INTERNACIONAL DE INVERSIÓN Y DÉFICITS FUNCIONALES}

El régimen de arbitraje internacional de inversión — me resisto a llamarle sistema en la medida que el término designa un conjunto ordenado de normas y procedimientos que no reúne este mecanismo- ha sido objeto de potentes críticas que orbitan sobre aspectos funcionales como sobre su propia legitimidad (Van Harten, 2007, capítulo 7). La crisis se basa, en última instancia, en la resistencia a reconocer que en el AII se discuten controversias que claramente escapan del ámbito privado y que constituyen un ejercicio de autoridad pública sobre las atribuciones de los Estados soberanos. 
En ese sentido, la literatura especializada coincide en que se trata de un mecanismo descentralizado de poder público (von Bogdandy y Venzke, 2013) o un ejemplo del derecho administrativo global (Van Harten y Loughlin, 2006).

Los déficits del AII pueden resumirse en cinco aspectos: 1. Es un sistema asimétri$\mathrm{Co}_{i} 2$. No propicia las garantías de independencia e imparcialidad en el juzgamiento; 3. Es un sistema poco transparente y participativo; 4 . No favorece la coherencia y la predictibilidad de las decisiones, y, $^{2}$. Los temas que se deciden están relacionados a cuestiones de derechos humanos y de política pública y, sin embargo, no existen medios de accountability — responsabilización—, ni se aplica de forma consistente el DIDH como fuente del derecho (Cervantes, 2017).

Se afirma que el sistema es asimétrico, porque los APPRI contienen obligaciones de trato a cargo del Estado receptor de la inversión mientras que el inversionista extranjero no suele asumir obligaciones ${ }^{3}$. Por otro lado, el sistema es asimétrico, porque, en la práctica, solamente los inversionistas extranjeros demandan a los Estados. Ello fomenta la idea de algunos autores de que se trata, verdaderamente, de una industria de servicio compuesta por una élite de árbitros que también ejercen la práctica de la abogacía, firmas internacionales de abogados que defienden tanto a Estados soberanos como a inversionistas extranjeros, y, finalmente, financiadores de litigios de terceros. De acuerdo con el informe del (CIADI, 2020) que es la institución que auspicia la mayor cantidad de All en el mundo, el $60 \%$ de casos con laudos de fondo favorecen parcial o totalmente al inversionista extranjero.

En segundo lugar, el arbitraje de inversión no favorece la apariencia de independencia e imparcialidad con los estándares que suelen tener los jueces al gozar de una remuneración fija, una dedicación exclusiva a su oficio y un periodo fijo determinado por la ley. Al contrario, se estima que existe un pequeño "mercado de árbitros" en el que solo 15 árbitros, procedentes de Europa, los EUA o Canadá, han resuelto el 55\% de todas las disputas conocidas basadas en TBIS. Por otra parte, los árbitros suelen asesorar también a inversionistas extranjeros o Estados soberanos en casos similares. Finalmente, se ha dicho que es preocupante que las recusaciones de un árbitro en el ámbito del CIADI sean resueltas por los otros miembros del tribunal, teniendo en cuenta que se trata de un grupo reducido y cohesionado (Fach Gómez, 2019; Eberhardt y Olivet, 2013; Commission, 2007, pp. 139-140).

En tercer lugar, se afirma que el arbitraje de inversión no es suficientemente transparente y participativo. Como destacan Ureña y Prada-Uribe (2019):

En sus inicios, el régimen de inversión extranjera presentó resistencia a la inclusión de amicus curiae o intervenciones de terceros como resultado de la lógica inicial heredada del arbitraje comercial internacional, la cual hacia énfasis en la naturaleza consensual y limitada del arbitraje. (p. 39)

3 Sin embargo, hay que mencionar los APPRI modernos suelen incluir obligaciones respecto de la legalidad de la inversión y la responsabilidad social empresarial. 
No obstante, como destaca la doctrina (Fach-Gómez, 2010), tanto la reforma al procedimiento CIADI del 2006 como del Reglamento CNUDMI del 2014 reconocen la publicidad de las audiencias y la posibilidad de presentar amicus curiae cuando la controversia sea de interés público. En todo caso, la literatura especializada insiste en que estas reformas son insuficientes pues prohíben el acceso a audiencias privadas y a documentos que no sean de dominio público, lo que limita severamente el rol del amicus curiae. Además, en el caso del CIADI, los laudos siguen siendo confidenciales. Por ello, Ureña y Prada-Uribe (2019) instan a que los tribunales constitucionales condicionen la ratificación de un APPRI a la inclusión de estándares rigurosos de publicidad.

En cuarto lugar, el arbitraje de inversión no favorece la coherencia y la predictibilidad de las decisiones pues se trata de tribunales ad hoc, carentes de un sistema de jerarquía entre ellos y sin un método de unificación formal de decisiones. Dada la ambigüedad y la textura abierta del lenguaje en la que están redactados los estándares de protección de los APPRI, la falta de predictibilidad en la interpretación de estos debe preocupar tanto a estados soberanos como a los propios inversionistas extranjeros. No existe consenso en el foro arbitral sobre si existe si quiera un deber informal de coherencia. Por ejemplo, en el caso Saipem S.p.A. c. Bangladesh (2007), se señaló:

El Tribunal considera que no está vinculado por decisiones anteriores. Al mismo tiempo, opina que debe tener debidamente en cuenta decisiones anteriores de tribunales internacionales. Considera que, salvo motivos contrarios imperiosos, tiene el deber de adoptar soluciones establecidas en una serie de casos coherentes. También considera que, con sujeción a los detalles de un tratado determinado y a las circunstancias del caso actual, tiene el deber de tratar de contribuir al desarrollo armonioso del Derecho de las inversiones y, por lo tanto, de satisfacer las expectativas legítimas de la comunidad de Estados e inversores en la seguridad del Estado de Derecho. (Decisión sobre competencia del 21 de marzo de 2007, párrafo 67)

Por otro lado, en el arbitraje SGS c. Filipinas (2004), se afirmó que cada tribunal debía ejercitar sus competencias de acuerdo con el derecho aplicable que es, por definición, diferente en razón de cada tratado bilateral de inversión. Además, se indicó que no existe una doctrina de precedente en el derecho internacional de las inversiones. En el arbitraje Enron c. Argentina (2004), se indicó que cada caso debía ser examinado a la luz de sus propias circunstancias y que no existía un deber de adherirse a decisiones dictadas en casos análogos. También en el arbitraje Fraport c. Filipinas (2006), se dijo que el significado de las cláusulas de un tratado debía determinarse individualmente a la luz del contexto, antecedentes de celebración, objeto, propósito y el lenguaje utilizado, por lo que las interpretaciones de otros tribunales no podían ser más que ilustrativas.

En síntesis, aunque la literatura argumente que el uso de los precedentes se ha vuelto constante y que tienen valor argumentativo, lo cierto es que no existen reglas formales para la unificación del significado de los estándares previstos en los tratados (Reinisch, 2008). Por ese motivo, es importante que los tribunales internacionales 
condicionen la ratificación de los APPRI a que se delimite mínimamente el alcance de estas nociones difusas.

En quinto lugar, se afirma en la literatura que los AII resuelven temas vinculados a la política pública del Estado y aspectos vinculados al respeto de los derechos humanos. Son frecuentes los casos relacionados con el derecho al acceso al agua, al ambiente sano, al derecho a la salud o medidas adoptadas en medio de una crisis económica. Sin embargo, los árbitros son reacios a incorporar el razonamiento del DIDH a la resolución de controversias y suelen argumentar que carecen de jurisdicción para pronunciarse sobre la aplicación de tratados de DDHH. En pocas palabras, voces doctrinales afirman (Hirsch, 2009) que el AII y los DDHH recorren caminos divergentes. Aquello resulta especialmente problemático dado que las decisiones arbitrales pueden provocar la modificación del ordenamiento jurídico nacional para evitar nuevas condenas o bien implicar el congelamiento del ordenamiento jurídico, incluso de terceros Estados, por temor de ser demandados bajo argumentos similares. Estos efectos se han visto, inter alia, en la regulación sobre la publicidad del empaque del tabaco (Moehlecke, 2020) y en las regulaciones ambientales que afectan la industria de los combustibles fósiles y la minería (Tienhaara, 2018).

\section{LA TENSIÓN ENTRE LOS DERECHOS HUMANOS Y EL ARBITRAJE DE INVERSIÓN Y LAS TENDENCIAS CONSTITUCIONALES EN AMÉRICA LATINA}

Lo primero que hay que considerar es que, aunque algunos autores hablan de un contragolpe (backlash) en contra del AII, lo cierto es que el régimen se mantendrá por su capacidad de adaptación y por ser una constante demanda de los países exportadores de capital (Langford, Behn y Fauchald, 2018). Ahora bien, es cierto que se están implementando una serie de medidas para limitar el poder interpretativo de los árbitros, entre otras: el arbitraje entre Estados para resolver las disputas interpretativas que puedan surgir en abstracto del APPRI, cuya decisión vinculará a los árbitros que decidan casos concretos en el futuro; la creación de comisiones interpretativas con representantes de los Estados involucrados (Ferreres, 2014), la tendencia a negociar contratos de inversión sujetos al derecho local en lugar de APPRI; la inclusión de cláusulas en los APPRI que introducen excepciones — generales o específicas — a los estándares de protección y cláusulas que proveen guías interpretativas del APPRI.

Igualmente, es importante mencionar las diversas propuestas como alternativa al arbitraje de inversión en el sentido de crear una corte regional de inversiones — la iniciativa de Ecuador ante la UNASUR que finalmente fracasó, principalmente, por motivos políticos - o alternativas mucho más ambiciosas como una auténtica Corte Multilateral de Inversiones (Cervantes, 2017). En esa misma línea, Van Harten, Titi (2017) y Howard (2017) han señalado que una Corte puede dotar el derecho internacional de las inversiones de coherencia y seguridad jurídica, así como eliminar las percepciones de falta de imparcialidad e independencia del arbitraje internacional. 
Del mismo modo, la doctrina parece concordar en que una reforma, por profunda que sea, no es suficiente para afrontar las objeciones al método de resolución de disputas actual y dan cuenta de iniciativas como las de la Unión Europea de crear órganos judiciales en el marco del CETA (Acuerdo entre Canadá y la Unión Europea) y la Asociación Transatlántica de Comercio e Inversión (TTIP, por sus siglas en inglés) entre la Unión Europea y Estados Unidos de América (cuya negociación, en general ha fracasado). Ciertamente algunos comentaristas se cuestionan de si se trata de una alternativa viable desde el punto de vista del acuerdo político requerido a nivel global - algunos se refieren a la propuesta de una Corte Multilateral de Inversiones como una utopía-, pero lo cierto es que las iniciativas arriba mencionadas dan cuenta de que se trata de una utopía realizable ${ }^{4}$.

Por otra parte, merecen mención las salidas más abruptas del Convenio CIADI por parte de países como Bolivia en 2007, Ecuador en el 2009 y Venezuela en el 2012. Como he detallado en otro trabajo (Cervantes, 2017), estas constituciones se inscriben en un determinado movimiento político-ideológico (el nuevo constitucionalismo latinoamericano y el socialismo del siglo XXI) y sus nuevos textos impulsaron la denuncia del tratado. Es curioso anotar que el rechazo constitucional al arbitraje se da en distinto grado. Por ejemplo, la constitución boliviana (Arts. 320 y 366) contiene una prohibición absoluta a recurrir al AII, mientras que la constitución ecuatoriana (art. 422) prevé excepciones cuando el arbitraje sea regional o administrado "por órganos jurisdiccionales de designación de los países signatarios" ${ }^{\prime \prime}$. Por último, la constitución venezolana (art. 151) es ambigua respecto de qué controversias pueden someterse o no a arbitraje en la medida que lo prohíbe en contratos de "interés público, si no fuere improcedente de acuerdo con la naturaleza de los mismos".

Como argumenta la doctrina, (Prieto, 2017) el caso ecuatoriano es demostrativo de la forma más drástica de rechazo al CIADI y una muestra palpable de como los tribunales constitucionales pueden incidir en el derecho internacional de las inversiones pues fue la Corte Constitucional de Ecuador la que declaró la incompatibilidad del arbitraje de inversión con la constitución de 2008. Por supuesto, no hay que pasar por alto que la mayoría de APPRI contienen cláusulas de supervivencia transitorias por lo que el recurso al arbitraje de inversión no está del todo descartado.

¿Qué es lo que condujo a este rechazo, sea drástico o moderado, en contra del AII? Una posible respuesta es la percepción de que se trata de una batalla desigual entre David — los Estados soberanos_y Goliat — el régimen de internacional de

4 Otros académicos, como Sornarajah (2016), se oponen a cualquier forma de protección internacional de las inversiones y señalan que se impondría una visión "neoliberal" del derecho aún con más autoridad y que los países del denominado "Sur-global" estarían infrarrepresentados. Baste anotar que la objeción se trata de una cuestión de diseño y, por tanto, contingente.

5 De hecho, existe una controversia interpretativa porque la constitución ecuatoriana prohíbe el arbitraje internacional en controversias contractuales o de índole comercial, que no es el caso del arbitraje de inversión en virtud de tratado. Sin embargo, la Corte Constitucional de Ecuador declaró los tratados vigentes como inconstitucionales y dispuso su denuncia (Fach Gómez, 2012). 
inversiones- (Fach Gómez, 2011). En efecto, existen casos paradigmáticos en los que se evidencia la tensión entre los DDHH y el AII en la medida que éste último limita seriamente la capacidad regulatoria de los Estados o, al menos, aumenta el costo de implementar nueva regulación.

Por ejemplo, los arbitrajes Pbillip Morris c. Australia (2012) y Pbillip Morris c. Uruguay (2016) en el que se alegó la violación del trato justo y equitativo y la expropiación de la inversión por regulaciones estrictas sobre la publicidad del tacado y la imposición de un modelo de presentación única del producto. Si bien las demandas fueron, en ambos casos, desestimadas no se puede ignorar que varios países retrasaron la implementación de las directivas de la OMS por temor a demandas similares.

Otro caso que ha llamado la atención pública es Aguas del Tunari c. Bolivia (2005) en el que el inversionista aumentó hasta en un 300\% las tarifas del suministro de agua tras la privatización del servicio, lo que condujo a una serie de manifestaciones sociales conocida como la "Guerra del Agua", lo que puso sobre la palestra pública la tensión entre el derecho al acceso al líquido vital y la posibilidad de privatizar las fuentes hídricas por un periodo de cuarenta años en favor de un privado. En el arbitraje Vattenfall c. Alemania (2012) se discute la lesión de los derechos del inversionista por una política estatal de transición a las energías limpias; el arbitraje Foreti c. Sudáfrica (2010) discute la compatibilidad de medidas de acción afirmativa para remediar el apartheid con los derechos de los inversionistas extranjeros; $y$, por supuesto, no se puede dejar de lado los múltiples casos de Argentina con motivo de medidas destinadas a aliviar la crisis económica.

En el ámbito suramericano resulta de especial interés los casos relacionados a la megaminería y la explotación petrolera y la tensión con los derechos de consulta previa de pueblos indígenas, así como con los derechos relacionados a la conservación del medio ambiente. Como han destacado varias voces doctrinales (Ureña y PradaUribe, 2019, p. 15):

Colombia no es ajena a esta problemática. Actualmente enfrenta una serie de demandas ante tribunales de arbitraje de inversión en las que necesariamente se ventilarán temas de interés público para todos los colombianos. Basta con mencionar las 3 demandas presentadas por las empresas mineras Cosigo Resources, Ltd, Cosigo Resources Sucursal Colombia, Tobie Mining and Energy (Tobie Mining), y Eco Oro Minerals Corp, las cuales tratan sobre medidas tomadas por el gobierno para proteger el medio ambiente. Además, la demanda de Tobie Mining también afecta los derechos de los pueblos indígenas que viven en el parque nacional natural Yaigoje-Apaporis, donde la empresa espera poder realizar la explotación de los recursos naturales.

En febrero de 2016, estas compañías presentaron formalmente una demanda arbitral contra el Estado colombiano por la expropiación sin compensación. De acuerdo con la reclamación, los accionantes buscaron una indemnización por $\$ 16.500$ millones de dólares, que corresponde al valor ponderado del oro que hubiera podido extraerse, 
más 11 millones de dólares por los gastos asumidos para la preparación del sitio y la obtención de la concesión minera. La controversia versa sobre la fecha de creación del Parque Nacional Natural Yaigojé-Apaporis, dos días antes de la licencia de concesión (Castro, 2017).

Visto el panorama general, hay que destacar que paulatinamente aumenta el interés y la literatura académica sobre el rol de los tribunales constitucionales en el AII (Titi, 2020; Puig, 2013; Fandiño-Bravo, 2014; Ureña y Prada-Uribe, 2019; KaufmannKohler y Potestà, 2020). La idea es, en definitiva, dejar de centrarse en el discurso de la fragmentación entre derecho de las inversiones y DIDH y, más bien, pasar a la interacción (Ureña, 2018) en el marco del Ius Constitutionale Commune para América Latina (Prieto, 2018). Por ese motivo, en el apartado siguiente de este artículo me propongo analizar los distintos mecanismos procesales para tender puentes entre el derecho constitucional y el arbitraje de inversión.

\section{EL ROL VIRTUOSO DE LA JUSTICIA CONSTITUCIONAL Y EL ARBITRAJE DE INVERSIÓN}

La poderosa voz de Hans Kelsen significó múltiples aportes fundamentales al derecho constitucional y quizá el más importante fue el denominado modelo europeo de control de constitucionalidad, teorizado y plasmado en la constitución austriaca de 1920 tras las cenizas de la Primera Guerra Mundial. Pero la criatura de Kelsen es hoy en día una institución bastante distinta y más compleja que la inicialmente prevista (Kelsen, 1928). Hoy los tribunales constitucionales no tienen la única función "pura" del control de constitucionalidad (Ferreres, 2011), sino que gozan de múltiples otras competencias que pueden interactuar con el AII. Si bien escribo estas páginas tomando el caso de Colombia como referencia, merece la pena notar que el modelo de justicia constitucional concentrado es dominante en toda América Latina y, por tanto, las discusiones son, guardando las distancias, de utilidad compartida.

Los tribunales constitucionales tienen, al menos, cinco competencias que tienen incidencia con el AII, estas son: 1. El control previo y abstracto de los tratados internacionales; 2 . Cuando se producen casos de jurisdicción concurrente $;$ 3. Cuando se controla la ejecución de un laudo arbitral No-CIADI $;$ 4. Cuando se realiza el control de constitucionalidad de la legislación o regulación que implementa un APPRI; y 5. Al realizar control concreto de los estados de excepción y de las medidas adoptadas durante la pandemia del covid-19. A continuación se tratarán cada una de estas competencias.

\section{El control previo y abstracto de los tratados internacionales}

El control de constitucionalidad de los tratados internacionales tiene como razón de ser el principio de supremacía constitucional. Se trata de la competencia más importante o la "piedra angular" en cuanto a la interacción con el AII dado que el resto de las competencias constitucionales se ejercitarán sujetas al panorama normativo 
previamente definido en el control de constitucionalidad sustancial de un APPRI (Ureña y Prada-Uribe, 2019, p. 18).

Como explica la doctrina (Bazán, 2006), en América Latina ${ }^{6}$ existen diversas modalidades de control de tratados internacionales, por ejemplo, concentrado o difuso ${ }^{7}$; preventivo y/o represivo ${ }^{8}$; obligatorio o facultativo ${ }^{9}$; o bien, obligatorio o facultativo según el tipo de tratado. Sin entrar aquí al análisis de los problemas jurídicos del control represivo de un tratado ${ }^{10}$, hay que mencionar que solamente los sistemas jurídicos que prevén un control de constitucionalidad previo, obligatorio y abstracto de tratados internacionales ${ }^{11}$ son idóneos para aliviar las tensiones existentes entre justicia constitucional y AII.

En términos generales, el control de constitucionalidad de los tratados internacionales en estos sistemas jurídicos se caracteriza por ser: control previo al perfeccionamiento del tratado; automático, en la medida de que el instrumento debe de ser puesto en conocimiento de la Corte Constitucional por la autoridad competente (generalmente, el ejecutivo) y en caso de incumplimiento la Corte Constitucional se pronunciará de oficio; babilitante, porque a falta de dictamen favorable de la justicia constitucional el Estado no puede obligarse internacionalmente; preventivo, pues la función del control es detectar anticipadamente antinomias con la constitución u otros tratados internacionales con rango constitucional o supraconstitucional (GóngoraMera, 2014); integral, porque se analizan los aspectos formales o de procedimiento, así como los aspectos sustantivos del tratado y del instrumento de ratificación. Por último,

6 Entendida como región sociocultural dentro del continente americano y compuesta por: Argentina, Bolivia, Brasil, Colombia, Costa Rica, Cuba, Ecuador, El Salvador, Guatemala, Haití, Honduras, México, Nicaragua, Panamá, Paraguay, República Dominicana, Uruguay, Venezuela y Chile.

7 Es el caso de Argentina, en el que el control de constitucionalidad es difuso y aplicado para un caso concreto. No existe control de constitucionalidad previo de los tratados internacionales (Highton, 2010). En Uruguay y Panamá tampoco existe un control previo de tratados internacionales por autoridad judicial.

8 Por ejemplo, en México, solo es posible atacar un tratado internacional por medio de un recurso de inconstitucionalidad con legitimación activa limitada o bien por medio de un recurso de amparo en casos concretos. No existe el control previo de constitucionalidad de tratados internacionales (Roa, 2001).

9 Es el caso de la constitución de Venezuela (1999), que en su artículo 336\#5 prevé que el presidente de la república o la asamblea nacional soliciten a la Sala Constitucional del Tribunal Supremo de Justicia su pronunciamiento sobre la constitucionalidad de un tratado internacional. También el caso de la Constitución de Guatemala (art. 272.E).

10 El control represivo de un tratado internacional puede generar responsabilidad internacional del Estado por violación de la Convención de Viena de 1969 sobre el Derecho de los Tratados, específicamente, de los artículos 26 y 27 de dicho instrumento, que tratan sobre la obligación de cumplir tratados de "buena fe" y sobre la imposibilidad de alegar el derecho interno para incumplir un tratado.

11 El control preventivo y abstracto de tratados internacionales se prevé en las constituciones de Costa Rica (art. 10.b. de la Constitución Política y artículo 96 de la ley de la jurisdicción constitucional), Bolivia (art. 202.9. Constitución Política del Estado), Ecuador (art. 438.1 de la Constitución), Perú (art. 200 de la Constitución Política), Chile (art. 93.1 de la Constitución Política); República Dominicana (art.185 de la constitución), Colombia (art. 241\#10 de la Constitución). 
tiene estado de cosa juzgada constitucional, lo que significa que no se podrá demandar la inconstitucionalidad posteriormente mientras permanezcan los fundamentos de hecho y de derecho de la decisión.

Como resalta la doctrina (Prieto, 2019), el rol usual de las cortes constitucionales se limitaba a hacer las veces de un semáforo, aprobando un APPRI, declarándolo constitucional — que es lo más frecuenta en la experiencia latinoamericana- o declarándolo inconstitucional con la consecuente prohibición de ratificación. En el caso colombiano, una alternativa distinta fue incorporar al análisis la doctrina de la interpretación conforme o de constitucionalidad condicionada, por la cual un tratado era válido en la medida que sea interpretado de una forma específica. Sin embargo, como destacan autores latinoamericanos (Ureña y Prada-Uribe, 2019, p. 20), el defecto de esta técnica es que:

no tiene ningún efecto ante un tribunal de arbitraje si esa decisión no se manifiesta en el tratado a través de una nota interpretativa, una enmienda, un protocolo adicional, o cualquier otra forma aceptada por el derecho internacional público.

Por ello, la virtud de la Sentencia C-252/119 de la CCC es que deja atrás ese concepto de mero trámite formal y sienta las bases para un rol proactivo y dialógico de la justicia constitucional en el AII. La solución que incorpora esta decisión es exigir, como condición para la ratificación, que el presidente de la República negocie una declaración interpretativa conjunta sobre cláusulas ambiguas o vagas contenidas en el APPRI entre Colombia y Francia, suscrito en 2014. Por otra parte, esta técnica desarrollada jurisprudencialmente en Colombia en 2019 ya aparece expresamente contemplada en otras legislaciones, como en la Ley Orgánica de Garantías Jurisdiccionales y Control Constitucional (2009) de Ecuador que dispone en lo pertinente:

Art. 112.-

2. Cuando se declara la inconstitucionalidad de uno de dichos tratados por razones de fondo, la Asamblea Nacional se abstendrá de aprobarlo hasta tanto se produzca la enmienda, reforma o cambio constitucional. De ser procedentes las reservas, se podrá aprobar cuando se las formule;

3. Cuando se declara la inconstitucionalidad por razones de forma, se deberá enmendar el vicio por el órgano que lo produjo $;$,

4. Cuando se declara la inconstitucionalidad de un tratado ya ratificado, el Estado deberá denunciar el tratado ante el órgano correspondiente, la orden de promover la renegociación del tratado, o promover la enmienda, reforma o cambio constitucional. 
Para dimensionar correctamente la importancia del cambio de precedente de la CCC es necesario hacer una referencia sobre el contexto particular del país respecto del AII. Colombia ha ratificado más de 24 APPRI y, de momento, mantiene 20 demandas de inversionistas extranjeros en arbitraje internacional, cuyas pretensiones suman USD. 9.525 millones (cifra que excede el presupuesto nacional del 2019) y que puede aumentar producto de intereses y costas. Además, al menos 9 demandas se sustentan "en la presunta causación de un hecho ilícito internacional a partir de sentencias emitidas por la propia Corte Constitucional, bien sea en proceso de tutela o en proceso de constitucionalidad" (Suárez, 2019).

Tomando en cuenta los efectos económicos de los laudos arbitrales en la economía nacional de un Estado latinoamericano, así como los efectos indirectos de los laudos arbitrales a nivel normativo interno, como instar a la reforma de leyes u otras regulaciones locales o bien generar un efecto de congelamiento en el sistema jurídico, se ha vuelto más necesario que nunca limitar el poder interpretativo de los árbitros internacionales.

Lo primero que merece destacarse, es que la CCC reconoce que el control de constitucionalidad previo de un APPRI no solamente es un proceso para verificar la compatibilidad de este con la norma fundamental, sino que constituye una oportunidad para enriquecer el debate y la deliberación en el proceso de celebración de los tratados, lo que se evidencia con las decenas de amicus curiae que intervinieron en el proceso (CCC, 2019, párr. 55). Esta primera apertura al diálogo ha sido destacada como uno de los mecanismos para paliar la denominada objeción contramayoritaria de la justicia constitucional (Roa, 2019). En efecto, entre más grupos de interés participen en el debate de los asuntos públicos es más probable alcanzar una decisión que tome en consideración todos los argumentos relevantes y que de otro modo podrían pasar desapercibidos (Nino, 1997). En palabras de Prieto (2019):

[...] detrás de la Sentencia C-252/19 se esconde un diálogo pluralista que se inició cuando se abrieron las puertas de los tribunales a diferentes expertos de dentro y fuera de Colombia. El objetivo era comprender mejor cómo debería funcionar el régimen internacional de inversiones. La corte, por primera vez en su historia, celebró una audiencia pública sobre este tema el 13 de diciembre de 2019, invitando a académicos, funcionarios públicos y al embajador de Francia en Colombia.

En segundo lugar, la premisa de la que parte la CCC sobre el rigor y alcance del control de constitucionalidad de los APPRI tiene en cuenta, por un lado, que los órganos políticos, como el ejecutivo y el legislativo merecen deferencia con motivo de su legitimidad democrática y representativa al momento de negociar y aprobar, respectivamente, un tratado internacional. Asimismo, la Corte nota que esa deferencia se justifica también sobre la materia del tratado que es técnica, como en la dificultad de prever las interpretaciones que a futuro se darán de las cláusulas del APPRI, debido a la naturaleza del sistema de AII (CCC, 2019, párr. 44). 
Sin perjuicio de lo dicho, la CCC indicó que, dada la necesidad de garantizar la supremacía constitucional y la existencia de un sistema de cuasi precedentes en el AII, es posible, al menos parcialmente, prever los efectos futuros de las cláusulas de los APPRI, por lo que decidió evaluar el APPRI entre Colombia y Francia, aplicando un juicio de razonabilidad (CCC, 2019, párr. 66).

Esto resulta bien interesante, pues la exigencia de elevar el estándar de control de constitucionalidad de los APPRI propuesta por la literatura (Ureña y Prada-Uribe, 2019, pp. 25-40) es parcialmente acogida por la sentencia de la CCC en comento. Así, la CCC indica que el juicio de razonabilidad implica verificar que (1) "las finalidades globales y de cada una de las cláusulas del tratado resulten legítimas a la luz de la Constitución"; (2) "que el tratado en su conjunto, así como las medidas individualmente previstas en dicho instrumento, sean idóneos, esto es, que existan elementos de juicio que permitan concluir que contribuirán a alcanzar sus finalidades"; y (3) que el tratado sea compatible con los derechos fundamentales, "los mandatos, valores y principios que aseguran la vigencia del Estado social" (CCC, 2019, párr. 65).

Esto, sin lugar a duda, implica un giro copernicano en el rol de la justicia constitucional respecto del derecho internacional de las inversiones, pues generalmente la conveniencia y oportunidad de los APPRI eran totalmente dejadas a criterio de las autoridades políticas y se presumía su idoneidad para el desarrollo económico y social del país. En cambio, la decisión en análisis reza que las ramas ejecutiva y legislativa, "en ejercicio de sus competencias, deben aportar razones y evidencia empírica, concreta y suficiente, que justifique la celebración de los mismos" (CCC, 2019, párr. 65).

En el caso concreto, la CCC estimó que, si bien no existía evidencia empírica concreta a favor o en contra de la conveniencia del APPRI para atraer IED, aquella debía deferir a la posición favorable del gobierno ${ }^{12}$ en razón de la información general sobre "la relevancia de los inversionistas e inversiones francesas en los flujos de IED global", "así como de su presencia y relevancia en la economía colombiana, habida cuenta de la magnitud de sus inversiones (ocupó el tercer lugar entre los inversionistas europeos en el país, entre 2004 y 2014)" y, en última instancia, "la legitimidad política de las ramas ejecutiva y legislativa de cara a la negociación de estos instrumentos" (CCC, 2019, párr. 108).

Como tercer punto de análisis, la CCC debió enfrentar una alegación de que el APPRI — siendo el argumento generalizable — era inconstitucional por lesivo del principio de igualdad formal y material previsto en la constitución. Ello por conceder una protección reforzada al inversionista extranjero directo que suele ser además un agente económico poderoso (CCC, 2019, párr. 109). Al respecto, la Corte anotó que:

12 Aunque existe vasta literatura que concluye que los Estados latinoamericanos son primordialmente perdedores en el arbitraje internacional y que no existe una relación proporcional entre la inversión extranjera directa recibida y las indemnizaciones originadas en laudos (Schultz y Dupont, 2014; Van Harten y Malysheuski, 2016). Por ejemplo, los Estados de Latinoamérica y el Caribe ocupan el $28,6 \%$ de las demandas conocidas; en el $70 \%$ de los casos gana el inversionista y el costo general de los casos equivale a aproximadamente $\$ 20,5$ billones de dólares (Olivet, Müller y Ghiotto, 2019). 
los recientes desarrollos del derecho internacional de inversiones consideran necesario que los AII también protejan al inversionista nacional en el sentido de que las autoridades públicas, en el marco de la regulación y el tratamiento de la inversión, otorguen un trato no menos favorable que el concedido al inversionista extranjero. (CCC, 2019, párr. 108)

Por ese motivo, luego de analizar experiencias comparadas como las del Consejo Constitucional francés al momento de estudiar la constitucionalidad del CETA o los desarrollos legislativos de Estados Unidos con el Trade Act de 2002, ambos, garantizando la igualdad entre el inversor extranjero y el nacional, la CCC concluyó que:

ninguna disposición del tratado en cuestión garantiza el mandato de igual trato al inversionista y a las inversiones nacionales en Colombia respecto del extranjero, así como la prohibición de discriminación en su contra, que, como se explicó, además de derivarse del artículo 13 de la Constitución Política, se han considerado necesarios en los recientes desarrollos del derecho internacional de inversiones. (CCC, 2019, párr. 118)

Con este argumento y antes de realizar un análisis pormenorizado del resto del tratado, la CCC lo declara condicionalmente constitucional, teniendo en cuenta que las finalidades que persigue son globalmente conformes con la norma fundamental, aunque requiere que el presidente negocie una declaración interpretativa a efectos de estipular que ninguna disposición del APPRI puede ser interpretada en el sentido de conceder un trato más favorable e injustificado al inversionista extranjero por sobre el nacional (CCC, 2019, párr. 109).

Sería imposible analizar aquí todos los aspectos de la Sentencia C-252/19 -la decisión tiene 223 páginas de extensión-por lo que me limitaré a realizar apuntes sobre los aspectos más salientes de aquella. En los aspectos específicos del APPRI, la CCC estableció condicionamientos para la ratificación de este, encargando al presidente la negociación de una declaración interpretativa. En el ámbito del estándar de trato justo y equitativo, el APPRI señala:

Cada una de las Partes Contratantes deberá otorgar un trato justo y equitativo de conformidad con el derecho internacional aplicable a los inversionistas de la otra Parte Contratante y a sus inversiones, en su territorio. Para mayor certeza, la obligación de otorgar un trato justo y equitativo incluye, inter alia:

a) La obligación de no denegar justicia en procedimientos civiles, penales o administrativos de conformidad con el principio del debido proceso.

b) La obligación de actuar de una manera transparente, no discriminatoria y no arbitraria respecto a los inversionistas de la otra Parte Contratante y sus Inversiones. 
Este trato es consistente con los principios de previsibilidad y la consideración de las expectativas legítimas de los inversionistas. (CCC, 2019, párr. 174)

Sobre este tema, la CCC señaló que la palabra inter alia debe interpretarse de forma restrictiva, en sentido meramente analógico sin que pueda entenderse que el Estado se compromete a diversas obligaciones más allá de las estipuladas. Similarmente, la expresión "de conformidad con el derecho internacional aplicable a los inversionistas de la otra Parte Contratante y a sus inversiones, en su territorio", se supedita a que su contenido se determine por las partes.

Por último, respecto del término "expectativas legítimas", la CCC precisó el alcance con el que el presidente debe negociar la declaración interpretativa. La Corte dijo que el término "expectativas legítimas" debe apreciarse "teniendo en cuenta que solo habrá lugar a estas siempre que se deriven de actos específicos y reiterados llevados a cabo por la Parte Contratante que induzcan al inversionista de buena fe a realizar o mantener la inversión y que se trate de cambios abruptos e inesperados efectuados por las autoridades públicas y que afecten su inversión".

En lo relativo al estándar de expropiación, el APPRI dispone:

Las medidas adoptadas por una Parte Contratante que son diseñadas para proteger objetivos legítimos de política pública, tales como la salud pública, la seguridad y la protección del medio ambiente, no constituyen expropiación indirecta, cuando sean necesarias y proporcionales a la luz de estos objetivos y se apliquen de tal de forma que respondan efectivamente a los objetivos de política pública para los que fueron diseñadas. (CCC, 2019, párr. 257)

En ese sentido, la Corte Constitucional estableció la condición de que la expresión "necesarias y proporcionales" debe interpretarse como respetuosa de "la libertad de configuración y la autonomía de las autoridades nacionales para efectos de, respectivamente, garantizar el orden público y proteger los objetivos legítimos de política pública". Ello, sin duda alguna, es una alusión al margen de apreciación nacional antes que a criterios más estrictos como el de proporcionalidad.

Finalmente, respecto del estándar de trato nacional y de la nación más favorecida, el APPRI dispone que a:

cada Parte Contratante le aplicará en su territorio a los inversionistas de la otra Parte Contratante, respecto de sus inversiones y actividades relacionadas con sus inversiones un trato no menos favorable que el concedido en situaciones similares a sus inversionistas o el trato concedido a los inversionistas de la nación más favorecida si este último es más favorable. (CCC, 2019, párr. 216)

Sobre esta cláusula, la CCC señaló que la expresión "situaciones similares" debía especificarse para garantizar la seguridad jurídica. En cuanto a la expresión de "trato", la CCC indicó que deberá preservarse "la competencia del Presidente de la República 
relativa a la dirección de las relaciones internacionales y la celebración de tratados" prevista en la constitución. El razonamiento específico de la CCC se ciñe a que:

En virtud del referido efecto cascada, la cláusula de NMF, en los términos previstos en el tratado en cuestión, es además incompatible con el carácter bilateral del tratado sub examine. Esto es así, por cuanto cualquier ventaja o condición beneficiosa que Colombia conceda a los inversionistas de un tercer Estado, en razón de las ventajas comparativas que puedan ofrecer y de la conveniencia nacional de cada negociación, les serán extensibles y aplicables a los inversionistas franceses. De esta manera, en los términos previstos en el tratado, la cláusula de NMF trae como consecuencia que el Presidente renuncie a la posibilidad de conceder beneficios o ventajas particulares a los inversionistas de otros Estados y, por tanto, a obtener ventajas comparativas en dichas negociaciones, con lo cual se afecta intensamente el libre ejercicio de la competencia prevista por el artículo 189.2 de la CP y se desconoce el carácter inter-partes de este APPRI. (CCC, 2019, párr. 252)

Como se puede apreciar, la actuación de CCC en la consolidación del régimen del derecho internacional de inversiones es realmente vanguardista y marca el derrotero para la región latinoamericana. Se trata, efectivamente, de una decisión que se aleja de extremismos, promueve la seguridad jurídica y el diálogo entre dos regímenes que habitualmente han sido disociados.

\section{La existencia de casos de jurisdicción concurrente}

La doctrina latinoamericana resalta que el derecho internacional de las inversiones conllevó el casi total abandono de la protección diplomática como medio de resolución de disputas entre el inversionista extranjero y el Estado receptor de la inversión (Ureña y Prada-Uribe, 2019) ${ }^{13}$. En sustitución, aunque de forma minoritaria, se incluyeron cláusulas que obligan al inversionista a agotar los recursos administrativos y/o jurisdiccionales locales antes de acudir al AII o que reconocían la exigencia de agotamiento de recursos internos como un derecho facultativo de los Estados ${ }^{14}$ (principio de subsidiariedad procedimental). Mientras que algunos autores ven este tipo de disposiciones un resurgimiento de la conocida doctrina Calvo (Schreuer, 2005), lo cierto es que representa una oportunidad ideal para reparar posibles violaciones de derechos a nivel local.

13 Por ejemplo, el Convenio CIADI estipula en el artículo 27: "Ningún Estado Contratante concederá protección diplomática ni promoverá reclamación internacional respecto de cualquier diferencia que uno de sus nacionales y otro Estado Contratante hayan consentido en someter o hayan sometido a arbitraje conforme a este Convenio".

14 Por ejemplo, el artículo 26 del Convenio CIADI estipula que: "Un Estado Contratante podrá exigir el agotamiento previo de sus vías administrativas o judiciales, como condición a su consentimiento al arbitraje conforme a este Convenio". 
No obstante, el panorama es por mucho más diverso hoy en día. Los APPRI pueden dispensar al inversor del requisito de agotamiento de los recursos internos — Van Harten $(2008,8)$ indica que esto es único en el derecho internacional de las inversiones- o bien pueden exigir un periodo de enfriamiento desde que se notifica el surgimiento de la disputa hasta el inicio del procedimiento contencioso con el fin de promover un acuerdo amistoso. Son más extrañas —y problemáticas — las denominadas "cláusulas de bifurcación del camino" por las cuales se exige al inversionista elegir entre el foro doméstico o el internacional. También es dable, de hecho, es lo que sucede generalmente, que el APPRI no contenga ninguna provisión respecto de este tema ${ }^{15}$.

A efectos de analizar el denominado problema de las jurisdicciones concurrentes hay que indicar que, aunque las cláusulas de bifurcación del camino existen para evitar que se litiguen los mismos hechos en el foro nacional e internacional, aquellas pueden ser defectuosas por la forma en la que están redactadas. Adicionalmente, hay que considerar que los litigantes a nivel local (por ejemplo, accionistas) no siempre coinciden con los litigantes a nivel internacional y que, incluso, pueden producirse solapamientos con otros regímenes internacionales como la jurisdicción de órganos de garantía regional de los derechos humanos ${ }^{16}$. Como han destacado Kaufmann-Kohler y Potestà, (2020, par. 117):

la lex lata no siempre es capaz de capturar la complejidad de las interacciones derivadas del hecho de que, aunque idénticas en sustancia, así como en términos económicos, la disputa ante los dos foros a menudo no es la "misma" en términos jurídicos (las partes a veces y con mayor frecuencia la base jurídica de las reclamaciones es diferente). Por lo tanto, de lege ferenda y en la medida en que los Estados la consideren su política para desalentar múltiples procedimientos sobre la misma medida, las cláusulas de bifurcación en el camino y de exención deben expresarse de manera más amplia y atender a estas situaciones. ${ }^{17}$

Por lo mismo, es factible que se produzcan solapamientos jurisdiccionales entre el derecho constitucional y el derecho internacional de las inversiones. Por ejemplo, Kaufmann-Kohler y Potestà (2020) mencionan la disputa arbitral entre la empresa estatal sueca Vattenfall c. la República Federal de Alemania (2012), derivada de la decisión

15 La inmensa mayoría de tratados de inversión no exige expresamente el agotamiento de recursos internos antes del inicio de un arbitraje internacional, sin embargo, tampoco establecen expresamente una exención al respecto. Contrario a lo que sucede en el contexto de los tratados internacionales de derechos humanos, en el que el agotamiento de recursos internos es la regla general, en el derecho internacional de las inversiones es la excepción. Este requisito solamente aparece en algunos tratados de primera generación y en otros más recientes firmados por Argentina, Rumania, Turquía, Emiratos Árabes Unidos y Uruguay (IISD, 2017, p. 10).

16 Por ejemplo, en el conocido caso Yukos c. Rusia además del arbitraje internacional de inversiones, el accionista principal de la compañía presentó una petición ante el Tribunal Europeo de Derechos Humanos, alegando, entre otras violaciones, la lesión del derecho a la propiedad y a no ser discriminado (Giupponi, 2017).

17 La traducción es propia. 
del Estado de eliminar gradualmente la energía nuclear. La inversionista inició un arbitraje CIADI bajo el tratado de la Carta de la Energía alegando que el cierre de las plantas nucleares requeridas por la ley de energía atómica alemana equivalía a una confiscación. Al mismo tiempo, la inversionista acudió al Tribunal Constitucional Federal de Alemania (Bundesverfassungsgericht, 2016), alegando la violación del derecho constitucional a la propiedad. Empero, el Tribunal Constitucional Federal consideró que la ley era mayoritariamente compatible con la ley fundamental de Bonn y que el cierre de las fábricas no equivalía a expropiación.

En el ámbito europeo es importante destacar los casos de España respecto de la Carta de la Energía en los que tanto el Tribunal Supremo como el Tribunal Constitucional se pronunciaron a favor del Estado y declararon que no existía violación alguna a las legítimas expectativas, seguridad jurídica e irretroactividad de los inversionistas extranjeros a raíz de los cambios en la regulación del marco de la energía solar que revirtió el sistema de incentivos económicos a las energías renovables. Sin embargo, España sí ha sido condenada por tribunales arbitrales ${ }^{18}$ en casos que versan sobre los mismos hechos bajo la alegación de la violación del trato justo y equitativo (Suciu, 2019).

Volviendo la mirada a América Latina, no es descabellado afirmar que todo Estado que reconozca un recurso sencillo, rápido y efectivo ante los tribunales en amparo de actos que violen los derechos fundamentales reconocidos por la constitución nacional o el Pacto de San José (Artículo 25, Convención Americana sobre Derechos Humanos, 1969) puede ser responsabilizado internacionalmente ante paneles de AII por las decisiones de altos tribunales nacionales.

Así, por ejemplo, en Colombia se reconoce la acción de tutela, así como las acciones populares y de grupo y este Estado ya enfrenta demandas de AII por sentencias de tutela que ordenan la reconexión o impiden el corte de energía a sujetos de especial protección constitucional (Gas Natural v. Colombia, caso CIADI n. ${ }^{\circ}$ UNCT/18/1) o una sentencia de inconstitucionalidad (Sentencia C-035 de 2016) por la cual la Corte Constitucional de Colombia prohíbe proyectos mineros en los páramos, en detrimento de las concesiones de explotación de recursos no renovables concedidas a inversionistas extranjeros (Eco Oro Minerals Corp c. Colombia, caso CIADI n. ${ }^{\circ}$ ARB/16/41). Estos son solo dos casos de más de una decena de disputas que se relacionan con decisiones de la Corte Constitucional de Colombia (Prieto-Ríos y Ureña, 2019).

Basta recordar aquí que la carga de casos del (CIADI, 2020, p. 23) refleja que el $32 \%$ de procesos iniciados son contra Estados de América del Sur — la región más demandada a nivel global—y que los sectores económicos de mayor demanda son la minería, el petróleo y el gas (30\%), seguido de la electricidad y otros tipos de 
energía (20\%). Siendo conscientes de que estas son las áreas primordiales de la IED en América Latina y de la coexistencia de grupos étnicos — con derecho a la consulta previa- y ambientalistas que reclaman la tutela de los DESCA que las constituciones latinoamericanas reconocen vigorosamente, la tensión entre las decisiones de tribunales constitucionales y los paneles de arbitraje es innegable. ¿Qué hacer ante un panorama de estas características?

Ureña y Prada-Uribe (2019) reconocen que existen dos soluciones alternativas: instar a que los árbitros reconozcan las normas de DDHH, haciendo uso del artículo 31(3)(C) de la Convención de Viena sobre la Interpretación de los Tratados (1969), según la cual los tratados deben ser interpretados a la luz de "toda forma pertinente de derecho internacional aplicable en las relaciones entre las partes"; o incluir las normas de DDHH como fuente del derecho en el respectivo APPRI.

El defecto de la primera solución es que no existe una jerarquía entre normas de DDHH y normas derivadas de APPRI, salvo en lo que respecta a normas de ius cogens cuya determinación es compleja y su potencial aplicativo es escaso. En segundo lugar, la Convención de Viena de 1969 exige que la norma de derecho internacional sea común a las partes y, en la práctica, las personas jurídicas que demandan a Estados latinoamericanos están domiciliadas en su mayoría en otros continentes como Europa o Asia. Esto hace que las normas que derivan del SIDH no sean comunes al no pertenecer estos Estados al mismo sistema.

La segunda alternativa consiste en que la justicia constitucional —y para eso hace falta un sistema de control previo y obligatorio de tratados que, como se ha visto, no predomina en la región - condicione la ratificación del tratado a que se negocie e incluya una cláusula en el APPRI que obligue a interpretar aquel instrumento a la luz del derecho internacional y regional de los DDHH. Sin embargo, a pesar de haber tenido ocasión para pronunciarse en este sentido, la CCC indicó en la sentencia C-252/119 que:

resulta inocuo e innecesario dictar orden alguna en el sentido de que, como lo solicita un interviniente, "la jurisdicción arbitral debe ser compatible con las obligaciones de derechos humanos adquiridas por Colombia". Esto, por cuanto, de suyo, tales órganos, así como cualquier cuerpo jurisdiccional a nivel internacional, tienen como fuente de derecho todas "las convenciones internacionales, sean generales o particulares, que establecen reglas expresamente reconocidas por los Estados litigantes", de conformidad con el artículo 38 del Estatuto de la Corte Internacional de Justicia. Dentro de tales convenciones se encuentran, por supuesto, las de derechos humanos, con lo cual la solicitud de condicionamiento referida pierde su razón de ser. (CCC, 2019, párr. 385)

Lamentablemente, el razonamiento de la CCC no toma en cuenta la disparidad entre regímenes de protección de DDHH, como se señaló arriba, e ignora que los árbitros son reticentes a incorporar el DIDH al momento de resolver las controversias. Entre tanto, es fundamental que los tribunales constitucionales incorporen en su razonamiento el derecho internacional de las inversiones al momento de ejercitar su jurisdicción. 
Ello puede tener un efecto preventivo o justificativo. Por ejemplo, en el caso ecuatoriano, la Corte Constitucional de Ecuador (2020) decidió en Dictamen n. ${ }^{\circ}$ 6-20 $\mathrm{CP} / 20$ que es constitucional realizar una consulta popular para decidir mantener o prohibir la actividad minera en determinadas zonas con fuentes hídricas; sin embargo, puntualizó que la decisión no tendría efectos retroactivos respecto de las licencias previas $^{19}$. Por otro lado, incorporar el razonamiento del derecho internacional de las inversiones al derecho constitucional puede sentar las bases para una deferencia de los paneles de arbitraje hacia la justicia nacional basada en una objetiva apreciación de los hechos y una razonable interpretación del derecho (Chazournes y McGarry, 2014 , p. 882). Lo dicho no excluye, por supuesto, la posibilidad de incluir cláusulas de este tipo en los APPRI.

\section{La ejecución de un laudo arbitral internacional no-CIADI}

Los tribunales constitucionales también pueden jugar un rol importante en la ejecución de un laudo arbitral internacional. Sin embargo, es preciso distinguir entre los dos regímenes de exequatur de laudos internacionales. El régimen más estricto es el que promueve el convenio CIADI, según el cual "Todo Estado Contratante reconocerá al laudo dictado conforme a este Convenio carácter obligatorio y hará ejecutar dentro de sus territorios las obligaciones pecuniarias impuestas por el laudo como si se tratare de una sentencia firme dictada por un tribunal existente en dicho Estado" (artículo 54.1).

Ureña y Prada-Uribe (2019, p. 23) señalan que sería factible ejercer una acción de tutela en contra de un laudo CIADI, precisamente, por tener carácter de sentencia en firme dictada por un tribunal del Estado. En efecto, las diferentes legislaciones reconocen acciones extraordinarias en contra de decisiones jurisdiccionales que constituyen cosa juzgada (piénsese en el amparo en España o en Perú, la acción de tutela en Colombia o la acción extraordinaria de protección en Ecuador). El objetivo de estas acciones es reparar las violaciones a los derechos del debido proceso u otros derechos fundamentales sustantivos en el trámite o decisión de un proceso judicial o arbitral-nacional. Sin embargo, discrepo en este punto pues hay que considerar el artículo 53 (1) del Convenio CIADI:

19 La Corte Constitucional de Ecuador señaló que: "60. El respeto del ordenamiento jurídico vigente y la aplicación de los cauces legales correspondientes no pueden ser inobservados a través de un proceso de democracia directa. Por lo que, ante una posible interpretación sobre un efecto retroactivo, que no ha quedado establecido ni ha cumplido con los requisitos para ser propuesto, la ciudadanía, las diversas instituciones del Estado, las concesionarias mineras, sus trabajadores e incluso la naturaleza, podrían enfrentar afectaciones a sus derechos. 61. En consecuencia, este Organismo Constitucional aclara que, en este caso, para evitar una interpretación ambigua, las preguntas sometidas a conocimiento del elector, en caso de obtener un resultado positivo, sólo podrán tener efectos hacia el futuro". 
El laudo será obligatorio para las partes y no podrá ser objeto de apelación ni de cualquier otro recurso, excepto en los casos previstos en este Convenio. Las partes lo acatarán y cumplirán en todos sus términos.

Dicho de otro modo, el Convenio CIADI proscribe cualquier medio impugnatorio por fuera del tratado. La anulación o declaratoria de inejecutabilidad por parte de la justicia constitucional irían en contra de otras provisiones explicitas del tratado que regulan estos aspectos. Más bien, una actuación de este tipo podría ser generadora de responsabilidad internacional y activar los mecanismos previstos en los artículos 27 y 64 del Convenio CIADI referentes, en su orden, a la posibilidad de brindar protección diplomática para la ejecución del laudo incumplido o someter el caso ante la Corte Internacional de Justicia. En esta línea y aunque la conclusión tenga cierto aire de tragedia, pertenecer al Convenio CIADI implica inexorablemente renunciar, en cierta medida, al principio de supremacía constitucional.

Por otro lado, el resto de los laudos arbitrales se sujetan a la Convención sobre el reconocimiento y ejecución de las sentencias arbitrales extranjeras de 1958, también conocida como la Convención de Nueva York. Esta convención permite discutir ante la justicia local del Estado donde se pretende homologar y ejecutar el laudo algunos aspectos sustantivos. Por ejemplo, es posible denegar la homologación y exequatur cuando el laudo violente el debido proceso o el orden público internacional o del país donde se pretende la ejecución (Penades y Tent, 2018).

No corresponde aquí desarrollar los aspectos principales de esta última excepción, basta con mencionar que, dada la carencia de guías interpretativas sobre el concepto de orden público, aquel permanece como uno de los conceptos más controvertidos del arbitraje internacional. Algunos Estados adoptan un concepto amplio en la que se incluyen los intereses nacionales y la soberanía mientras que otros Estados adoptan un concepto restringido a los principios básicos de moralidad y justicia, partiendo de la base de no imponer visiones parroquiales como freno a la intención de las partes de someterse a arbitraje (Van Den Berg, 2007). Lo que sí corresponde anotar es la necesidad de profundizar el significado del orden público regional a la luz del ius constitutionale commune existente en América Latina, clarificando ese concepto difuso y dotándolo de contenidos precisos.

\section{El control de constitucionalidad abstracto de la legislación o regulación que implementa un APPRI}

Ureña y Prada-Uribe (2019) comentan que los APPRI suelen contener normas que no son autoejecutables, sino que requieren de posteriores actos legislativos y, en general, regulatorios por parte del Estado receptor de la inversión. En ese sentido, se ha destacado que el control previo, obligatorio y abstracto de los APPRI no obsta el control constitucional de estos actos posteriores. En esa línea, la Corte Constitucional de Colombia (Sentencia T-055 de 2014) ha indicado que: 
las futuras ejecuciones legislativas y administrativas del instrumento internacional deben ser conformes con la Constitución. En efecto, es usual que ciertas disposiciones consagradas en tratados internacionales tengan carácter, en términos de la doctrina americana y seguida por la europea, de normas non-self-executing, esto es, que para poder desplegar todos sus efectos en el ordenamiento interno de un Estado requieran del correspondiente desarrollo normativo, a diferencia de aquellas que son self-executing o autoejecutables. Así pues, aquellas disposiciones con rango legal o reglamentario que permitan la debida ejecución interna de un tratado internacional de libre comercio, deberán ser sometidas a los correspondientes controles judiciales.

Hay que tener en consideración que dicha regulación puede ser impugnada por acciones de inconstitucionalidad abstracta o surgidas de casos concretos en el caso de la consulta de constitucionalidad generalmente permitidas en los sistemas de justicia constitucional concentrada. Por ello, el control previo, obligatorio y abstracto de los APPRI debe tener un estándar exigente y obligar a la incorporación de normas de DDHH y deben dejar suficiente margen al poder de regulación de los Estados soberanos. En caso contrario, el control de constitucionalidad de los actos legislativos o regulatorios subsecuentes podría apreciarse como una violación de estándares como el trato justo y equitativo en su dimensión de expectativas legítimas basadas en un marco regulatorio estable.

\section{El control constitucional concreto de los estados de excepción y de las medidas adoptadas durante la pandemia de la covid-19}

El Informe sobre las Inversiones en el Mundo del año 2020 de las Naciones Unidas (World Investment Report 2020) indica que el derecho internacional de las inversiones y el arbitraje no son ajenos a la pandemia. De este modo, se pone de manifiesto que las negociaciones de varios APPRI se han visto ralentizadas o suspendidas. También se ha destacado la necesidad de incluir un margen suficiente de maniobra a los Estados en estos tratados a fin de proteger la salud pública y minimizar los riesgos asociados a los procedimientos de resolución de controversias (UNCTAD, 2020a, p. 20). Igualmente, se ha identificado que la covid-19 afecta de forma intensa la inversión extranjera y se predice una caída drástica en los flujos de inversión durante los años 2020-2021 de alrededor de un $40 \%$ en cuanto al promedio, lo que significa el nivel más bajo de flujos de inversión a nivel mundial en las últimas dos décadas.

Se ha advertido que las medidas estatales en el marco de la pandemia tienen el potencial de detonar demandas de AII, aunque vale decirlo, buena parte de estas medidas se amparan en las recomendaciones de la OMS y siendo una situación imprevisible, existe consenso sobre las altas posibilidades de éxito de defensa estatal con alegaciones fundamentadas en los artículos sobre responsabilidad del Estado por hechos internacionalmente ilícitos (Asamblea General ONU, 2001) como fuerza mayor, estado de necesidad, peligro extremo o el ejercicio legítimo de los poderes 
de policía del Estado receptor de la inversión (Chaisse, 2020). En todo caso, veremos que las medidas estatales pueden ser evaluadas desde dos estándares disímiles: la proporcionalidad estricta o el margen de apreciación nacional.

Por otro lado, Bjørnskov y Voigt (2018) afirman que el 90\% de las constituciones vigentes contienen disposiciones relativas a poderes de emergencia o estados de excepción. Lógicamente, la pandemia obligó a que los países alrededor del mundo declarasen estados de excepción o emitieran regulaciones de emergencia. Así, en el ámbito interamericano, al menos trece Estados han notificado a la OEA la declaración de estados excepcionales — es el caso de Argentina, Bolivia, Chile, Colombia, Ecuador, El Salvador, Guatemala, Honduras, Panamá, Paraguay, Perú, República Dominicana y Surinam- (Cervantes, Matarrita y Reca, 2020).

Respecto del control institucional sobre la autoridad ejecutiva que asume poderes excepcionales, existen modelos que implantan un control político generalmente a cargo del legislativo, modelos que encargan el control de la declaratoria del estado de excepción y de las medidas de implementación de este a autoridades judiciales como los tribunales constitucionales $\mathrm{y}$, finalmente, modelos mixtos que combinan tanto el control político como jurisdiccional. A los efectos de este artículo, conviene limitarse al análisis del rol de los tribunales constitucionales en el control de las medidas adoptadas con motivo de la covid-19 y su relación con el AII.

¿Cómo pueden contribuir efectivamente los tribunales constitucionales a prevenir demandas de arbitraje internacional en el contexto de la pandemia? Varios autores (von Bogdandy, Casal y Morales Antoniazzi, 2020, pp.61-69) han señalado recientemente en un extenso e interesantísimo trabajo sobre la pandemia de la covid-19 y el Estado de Derecho que países como Ecuador, Colombia y Venezuela tienen sistemas de control automático de constitucionalidad sobre la declaratoria de estados de excepción y las medidas que se adopten con motivo de este. Asimismo, también existen sistemas en los que el control sobre el estado de excepción y de las medidas adoptadas con motivo de este solo puede ser iniciado a petición de parte o incidentalmente por medio de otra garantía jurisdiccional como amparos o babeas corpus. Este sería el caso de países como Perú, Chile, El Salvador, Guatemala, Brasil o Argentina.

De cualquier modo, vale anotar que al igual que el control previo y abstracto de tratados internacionales, el control constitucional automático de los estados excepcionales y de las medidas que se adopten con motivo de este tampoco es una tendencia mayoritaria en Latinoamérica. La idea que defiendo es que este tipo de sistemas jurídicos está en mejor posición para prevenir futuras demandas de AII o bien servir como justificación en la medida que ponderen razonablemente los intereses estatales y del inversionista extranjero. De este modo, los tribunales constitucionales pueden exigir una especial justificación para la adopción de una medida a priori lesiva de los derechos del inversionista.

Por ejemplo, en el caso de Ecuador, el presidente de la República dispuso una recaudación anticipada de tributos a los grandes contribuyentes en el marco de la pandemia. Sin embargo, la Corte Constitucional del Ecuador (2020) negó aquella recaudación 
anticipada por no haberse justificado el destino de aquellos fondos. Posteriormente, el presidente presentó a la Corte un nuevo decreto en el que se explicitaba la finalidad legítima de la recaudación y la manera en que se utilizarían los fondos exclusivamente para la gestión de la covid-19 y no para sufragar el gasto corriente. Como se puede apreciar, la actuación de los tribunales constitucionales puede servir para evitar tratos arbitrarios o discriminatorios hacia inversionistas nacionales y extranjeros, además de fortalecer la viabilidad de argumentos como la fuerza mayor, el peligro extremo o el estado de necesidad.

Ahora bien, para comprender la virtud de la justicia constitucional en este ámbito hace falta primero comprender el problema de las medidas estatales potencialmente lesivas de los derechos del inversionista extranjero. A continuación, algunos casos ilustrativos como el de Estados Unidos que, en virtud de la ley de defensa de la producción de 1959, obligó a la compañía General Motors a cambiar su giro de negocio y a producir insumos para la gestión de la covid-19. Por otro lado, en España, mediante Real-decreto 463/2020, se admitió la posibilidad de intervenir temporalmente fábricas, unidades de producción e instalaciones hospitalarias, además de permitir la requisición de todo tipo de bienes. Igualmente, el Consejo Federal en Suiza posibilitó la regulación artificial de la oferta y demanda de bienes y la posibilidad de expropiar bienes relacionados a la industria sanitaria, proveyendo únicamente una indemnización sobre el costo del producto (UNCTAD, 2020b).

En el ámbito de la propiedad intelectual, varios Estados _Canadá, Chile, Ecuador, Alemania - implementaron medidas para la concesión de licencias no voluntarias sobre patentes a efectos de potenciar la investigación sobre la pandemia de la covid-19. Sobre estas cuestiones, abogados de firmas internacionales especializadas como Alston \& Bird Lawyer y Hogan Lovells han afirmado que obligar a los productores a vender drogas a precios significativamente reducidos y/o tomar la propiedad intelectual por sí mismos y/o difundir esa propiedad intelectual a terceros sin permiso podría dar lugar a reclamaciones de expropiación en virtud de tratados de inversión y que la "imposición de un tope a los precios" para los suministros médicos también se identifica como un objetivo de reclamaciones relacionadas con el coronavirus por parte de inversores extranjeros, ya que "pueden reducir drásticamente los ingresos por ventas" (Corporate Europe Observatory, 2020).

Este tipo de regulaciones estatales podrían ser interpretadas como contrarias al estándar de trato justo y equitativo —uno de los conceptos más problemáticos del derecho internacional de las inversiones - por lo que la (UNCTAD, 2020b) promueve negociar APPRI con cláusulas que reconozcan que el trato justo y equitativo a la IED no impide al Estado promulgar regulaciones de buena fe con motivo de cumplir objetivos legítimos de política pública. Igualmente, la intervención de unidades de producción y la requisición de bienes y servicios pueden ser interpretadas como una confiscación en la medida en que no se indemnice el daño lucro cesante o las "expectativas legítimas", sino únicamente el "costo de producción". De allí que la UNCTAD (2020b) promueva clarificar que tipo de indemnización corresponde en estos supuestos excepcionales. 
Por otra parte, existe una tendencia mundial a realizar inyecciones de capital o salvatajes a las pequeñas y medianas empresas que, de acuerdo con los líderes del G20, se trata de una inversión de más de cinco trillones de dólares en la economía mundial. Este tipo de medidas podrían interpretarse como lesivas del principio de trato conforme a la nación más favorecida en cuanto brinda tratos más favorables a inversionistas nacionales en detrimento de extranjeros. Por ese motivo, la UNCTAD (2020b) promueve que sectores específicos, como la salud o el medio ambiente, sean expresamente excluidos del ámbito de aplicación de este estándar.

Podríamos seguir enunciando medidas estatales que presuntivamente lesionen los derechos del inversionista extranjero como la orden de cierre de hoteles, restaurantes, gimnasios, cines, centros comerciales, transporte aéreo ${ }^{20} \mathrm{y}$, en general, los denominados servicios no esenciales. Asimismo, dada la naturaleza de la pandemia y de las recomendaciones básicas para prevenir el contagio, como lavarse frecuentemente las manos, múltiples gobiernos como El Salvador, Bolivia, Colombia, Honduras, Paraguay y Argentina han suspendido temporalmente el cobro de tarifas de servicios básicos de agua que suelen estar concesionados a inversionistas extranjeros (Serrano y Gutiérrez, 2020).

Tampoco se pueden ignorar las múltiples medidas estatales en el ámbito bancario y financiero que suspenden el cobro de créditos o procesos de declaratoria de insolvencia —en Italia, España, Alemania, Bélgica y múltiples estados latinoamericanosque potencialmente pueden afectar al capital extranjero. Y en el ámbito tributario, el establecimiento de exenciones de impuestos a sectores productivos específicos puede ser considerado discriminatorio por los inversionistas extranjeros, quienes también han levantado una protesta por proyectos de ley que buscan crear tributos o aumentar la tasa impositiva prexistente para paliar los efectos económicos de la covid-19 (Corporate Europe Observatory, 2020). Resulta de especial interés el caso de Perú, que es el primer país formalmente notificado con un reclamo ligado a la covid-19. Como señala Bas (2020):

En América del Sur se destaca el caso de Perú, octavo Estado en el mundo en número de contagios y segundo en el continente con 214.788 casos y 6.088 fallecidos al 12 de junio de 2020 (Universidad Johns Hopkins). Mediante la sanción de la Ley 31.018 (7 de mayo de 2020), el Congreso Peruano determinó la suspensión del cobro de peajes durante el estado de emergencia, hecho que despertó la alarma entre diferentes sectores políticos respecto a las eventuales demandas de los accionistas extranjeros de las concesionarias de peajes. Este hecho se refuerza con la nota conjunta enviada al Presidente del Congreso por parte de las Embajadas de Canadá, Australia, Francia y Colombia en la que manifiestan

20 A raíz del cierre de fronteras, la Asociación del Transporte Aéreo Internacional prevé pérdidas de ingresos globales para las compañías aéreas en 2020 de entre USD 63 mil millones y USD 113 mil millones (Bernasconi-Osterwalder, Brewin y Maina, 2020). 
preocupación por medidas como la mencionada que "vulneran seriamente la estabilidad y seguridad jurídica y contractual" y afecta las inversiones de empresas de su nacionalidad.

Lo expuesto hasta el momento pone de manifiesto que la preocupación a raíz de la pandemia de la covid-19 y su relación con el AIl no es en absoluto teórica, sino que tendrá importantes efectos en la economía mundial. Algunos autores se refieren inclusive a que podríamos estar ante un punto de inflexión del régimen de AII. Frente a esta apremiante crisis sanitaria, social y económica, un grupo de académicos y miembros de la sociedad civil, liderados por el Columbia Center on Sustainable Investment han solicitado una moratoria en la tramitación de todos los arbitrajes de inversión en contra de Estados y una restricción permanente en "todas las reclamaciones de arbitraje relacionadas con medidas gubernamentales dirigidas a las dimensiones sanitaria, económica y social de la pandemia y sus efectos" (CCSI, 2020).

Otros gobiernos, como Bolivia, han solicitado la suspensión de la tramitación de cuatro procesos de arbitraje de inversión, alegando la imposibilidad de reunir y presentar documentos para la defensa, debido a las complicaciones generadas por la covid-19. Igualmente, Guatemala solicitó la suspensión del pago de un laudo por la cuantía de aproximadamente \$36 millones de dólares, alegando la necesidad de priorizar esos fondos en la gestión de la crisis. Todas estas peticiones han sido rechazadas (Olivet y Müller, 2020).

Incluso, el 2 de abril de 2020, la Asamblea General de la ONU aprobó por unanimidad una resolución que reconoce "los efectos sin precedentes" de la pandemia y pide que se intensifique la cooperación internacional para contener, mitigar y derrotar la covid-19 y su impacto social, económico y financiero adverso en todas las sociedades. Lamentablemente, este tipo de propuestas son abiertamente utópicas. El arbitraje de inversión llegó para quedarse y ha sobrevivido a pesar de los múltiples intentos de reforma, por lo que el derecho constitucional debe ser capaz de utilizar las limitadas herramientas con las que cuenta a fin de alivianar las tensiones entre estos dos regímenes.

Como se dijo arriba, las medidas estatales adoptadas en medio de la pandemia pueden ser evaluadas desde dos estándares distintos. Por ejemplo, podría exigirse la aplicación del método de la ponderación que, como es conocido, exige que la medida en cuestión sea necesaria para un fin legítimo; que sea idónea, es decir, que sea la opción empíricamente más eficaz para lograr el objetivo propuesto y, finalmente, que sea estrictamente proporcional, lo que significa que se adopte el medio menos lesivo para otros intereses legítimos y derechos en juego (Kingsbury y Schill, 2010). Por el contrario, podría alegarse que el estándar a aplicar para evaluar las medidas estatales adoptadas con motivo de la covid-19 no debe ser el de proporcionalidad estricta ${ }^{21}$, 
sino que debe concederse a los Estados un razonable margen nacional de apreciación (Shany, 2005), tomando en cuenta la escasa información sobre el virus, sus efectos y la existencia de diferentes estrategias para afrontar la crisis en cada país y los diferentes intereses nacionales en juego 22 .

Desde mi perspectiva, la justicia constitucional puede coadyuvar a prevenir demandas arbitrales internacionales, realizando un control más riguroso, bajo el esquema del principio de proporcionalidad, de las medidas adoptadas durante la emergencia de la covid-19. Por otro lado, también puede ser deferente y reconocer un margen de apreciación gubernamental basado en la capacidad técnica del ejecutivo y los diferentes medios razonables para lograr fines legítimos en panoramas variables y con información limitada, como sucede con la pandemia. Considerar a nivel local los intereses de los inversionistas puede además sentar las bases para una defensa exitosa a nivel internacional.

Ahora bien, lo dicho no es realmente una solución definitiva — las que se requieren son por mucho más drásticas — sino tan solo un paliativo, pues, aunque los Estados se defiendan argumentando causales de exclusión de la antijuricidad de su actuación, lo cierto es que no existe un sistema de precedentes fuerte en el arbitraje internacional de inversión, sino que cada tribunal actúa de forma ad boc para la resolución de un caso concreto. Ello puede implicar interpretaciones distintas, incluso bajo un mismo APPRI, idénticas partes en litigio y hechos similares en cuanto a la controversia. Aunque desde el optimismo, también se puede apostar por la consolidación de un sistema de cuasiprecedentes basado en la fuerza del mejor argumento (Prieto, 2019).

\section{CONCLUSIÓN}

La interacción entre la justicia constitucional y el arbitraje internacional de inversión es innegable. Sin embargo, los paneles arbitrales son, generalmente, reacios a incorporar argumentos del DIDH a las controversias que deciden. Por ese motivo, la función

no neutral (Vadi, 2015). Sin embargo, no se puede ignorar que, dada la vaguedad del lenguaje de los TBI, el principio de proporcionalidad puede contribuir a racionalizar las decisiones antes que ir en detrimento de la argumentación de aquellas. Además, el principio de proporcionalidad puede servir también como defensa del Estado. Finalmente, la doctrina mayoritariamente concluye que el principio de proporcionalidad debe ser aplicado en el derecho internacional de las inversiones y que forma parte del derecho internacional público general (Sweet y Cananea, 2014).

22 Aunque la doctrina se encuentra dividida sobre la plausibilidad de utilizar la doctrina del margen de apreciación nacional desarrollado por el TEDH y trasponerlo al ámbito del arbitraje de inversión. Las razones podrían resumirse en que podría utilizarse como excusa para evitar un análisis pormenorizado del caso o que podría contribuir aún más a la fragmentación del arbitraje de inversión (Arato, 2014). Por su parte, (Born, Morris \& Forrest, 2020) argumentan que puede conducir a decisiones arbitrarias y que el derecho internacional de inversiones tiene como deber objetivo determinar si un estado violó o no un tratado internacional, no existiendo lugar para la discreción. También hay autores que sostienen que el margen de apreciación nacional es una técnica del derecho internacional público en general (Shany, 2005) y, finalmente, hasta los autores críticos reconocen que esta doctrina ha sido expresamente aplicada en el arbitraje de inversión (Zarra, 2017). 
encomendada a los guardianes de la constitución es tanto virtuosa como fundamental en la medida de que aquellos pueden intervenir de forma preventiva y condicionar la ratificación de un APPRI a la negociación de declaraciones interpretativas conjuntas o inclusive exigir la negociación de cláusulas relativas a la aplicación del derecho internacional de los derechos humanos, estándares mínimos de transparencia y publicidad procesal e incluso una cláusula de deferencia con las decisiones judiciales internas.

Pero ese rol preventivo y virtuoso de la justicia constitucional solo puede florecer en sistemas jurídicos con un control de constitucionalidad previo, abstracto y obligatorio de los tratados internacionales que, además, sea altamente participativo. No obstante, la realidad en el constitucionalismo latinoamericano actual apunta que solamente pocos estados - Costa Rica, Bolivia, Ecuador, Perú, Chile, República Dominicana, Colombia- cuentan con un sistema de estas características. De allí que el primer desafío para paliar los efectos negativos del arbitraje de inversión y sentar las bases para un diálogo entre jueces y árbitros sea una transformación constitucional generalizada en este aspecto particular.

Por otro lado, es innegable que el razonamiento constitucional ha migrado, aunque no de forma estable, al derecho internacional de las inversiones, como demuestra la incorporación del principio de proporcionalidad o la doctrina del margen de apreciación nacional al razonamiento arbitral. Y a la inversa, la Sentencia C-252/19 de la CCC es demostrativa de que el razonamiento del derecho internacional de las inversiones también puede ser incorporado en el análisis constitucional. Finalmente, la pandemia de la covid-19 supone un punto de inflexión respecto de las condiciones en las que se desenvuelve el AII.

Las medidas que adoptan los gobiernos para paliar la crisis sanitaria pueden y, de hecho, afectan los intereses de los inversionistas extranjeros. Por ello, si la justicia constitucional se toma en serio los derechos del inversionista extranjero puede prevenir o justificar la responsabilidad del Estado en estos aspectos. Parece entonces que en perspectiva 2030, el discurso de lo público será dominante en el mantenimiento, reforma o debilitamiento del arbitraje de inversión. En línea con lo expuesto, se puede anticipar un aumento de demandas directamente relacionadas a estos eventos. En ese sentido, uno de los principales desafíos y debates será analizar el alcance de la defensa de los poderes de policía del Estado bajo un estándar como el del margen de apreciación nacional o, por el contrario, bajo un examen estricto de proporcionalidad, así como revivir el debate sobre la fuerza mayor, el caso fortuito y el estado de necesidad como eximentes de responsabilidad internacional del Estado.

\section{REFERENCIAS}

ARATO, J. (2014). The margin of appreciation in international investment law. Virginia Journal of International Law, 54(3), 545-578.

BAZÁN, V. (2006). El control de constitucionalidad de los tratados internacionales en América Latina. Estudios Constitucionales, 4(2), 509-554. 
Bernasconi-Osterwalder, N., Brewin, S. y Maina, N. Protección ante reclamaciones entre Inversor y Estado en tiempos de la covid-19: 1lamado a la acción para los gobiernos. En International Institute for Sustainable Development. https://bit.ly/2G5891Z

BJøRNSKOV, C. y VOIGT, S. (2018). The architecture of emergency constitutions. International Journal of Constitutional Law, 16, Issue 1,101-127.

Born, G., MOrRIS, D. y Forrest, S. (2020). A margin of appreciation: Appreciating its irrelevance in international law. Harvard International Law Journal, 61(1), 65-134.

Castro, M. N. (2017). El Estado colombiano ante un arbitraje internacional de inversión. Revista Derecho del Estado (38), 23-66.

Cervantes, A. (2017). Nuevo Constitucionalismo Latinoamericano y Arbitraje de Inversión. Spain Arbitration Review (30), 81-100.

Cervantes, A., Matarrita, M. y RecA, S. Los estados de excepción en tiempos de pandemia: un estudio comparado en América Latina. Cuadernos Manuel Giménez Abad (20), 180-206.

Chaisse, J. (2020). Both Possible and Improbable-Could COVID-19 Measures Give Rise to Investor-State Disputes? Contemporary Asia Arbitration Journal, 13(1), 99-184.

ChazOURnes, L. y MCGARRY, B. (2014). What roles can constitutional law play in investment arbitration? Journal of World Investment \& Trade, 15(5-6), 862-888.

Commission, JefFrey P. (2007). Precedent in Investment Treaty Arbitration-A Citation Analysis of a Developing Jurisprudence. J. Int'l Arb., 24(2), 129-158.

Olivet, C. y Eberhardt, P. (2013). Cuando la injusticia es negocio. Cómo las firmas de abogados, árbitros y financiadores alimentan el auge del arbitraje de inversiones. En Corporate Europe Observatory y Transnational Institute. https://bit.ly/37MX8kI

FACH GÓmEZ, K. (2010). Proponiendo un decálogo conciliador para Latinoamérica y CiADI. Revista Facultad de Derecho y Ciencias Políticas, 40(113), 439-454.

FACH GÓmEZ, K. (2011). Latin America and icsid: David versus goliath. Law and Business Review of the Americas, 17(2), 195-230.

FACH GÓmEZ, K. (2012). Ecuador's attainment of the Sumak Kawsay and the role assigned to international Arbitration. Yearbook on International Investment Law 2010-2011.

FACH GÓmEZ, K. (2019). Key Duties of International Investment Arbitrators. A Transnational Study of Legal and Etbical Dilemmas. Springer.

FACH GÓmEZ, K. (2020). Drafting a Twenty-First Century Code of Conduct for International Investment Adjudicators. En J. Chaisse, L. Choukroune y S. Jusoh, (eds.), Handbook of International Investment Law and Policy, 2020.

FAndiÑO-BRAVO, J. C. (2014). LL. M. THESIS: The Role of Constitutional Courts in International Investment Law and Investment Treaty Arbitration: A Latin American Perspective. Max Planck Yearbook of United Nations Law Online, 18(1), 667-745.

FEbles PozO, N. (2019). La transparencia en el arbitraje internacional y en los tratados bilaterales de inversión. Cadernos de Dereito Actual, 12, 57-95.

Ferreres, V. (2011). Una defensa del modelo europeo de control de constitucionalidad. Marcial Pons.

Ferreres, V. (2015). Arbitraje, democracia y Estado de derecho: algunas reflexiones sobre la teoría de Owen Fiss. En O. Fiss et al. (pp. 151-172), SELA, 20 años pensando en los derechos y la democracia. $10^{\circ}$ ed. Libraria. 
GiupponI, B. (2017). Disentangling Human Rights and Investor's Rights in International Adjudication: The legacy of the Yukos Cases. Willamette Journal of International Law and Dispute Resolution, 24(2), 127-168.

GÓnGOra Mera, M. (2014). La difusión del bloque de constitucionalidad en la jurisprudencia latinoamericana y su potencial en la construcción del ius constitutionale commune latinoamericano. En A. Von Bogdandy, H. FiX-Fierro y M. AnTONIAZZI (coords.), Ius constitutionale commune en América Latina. Rasgos, Potencialidades y Desafíos (pp. 301-327). IIJ/ UNAM e Instituto Max Planck de Derecho Público Comparado y Derecho Internacional.

Highton, E. (2010). Sistemas concentrado y difuso de control de constitucionalidad. En A. Bogdandy, E. Ferrer MaC-Gregor y M. Morales Antoniazzi (ed.), La justicia constitucional y su internacionalización. ¿Hacia una ius constitutionale commune en América Latina? 1, 107-173.

HiRSCH, M. (2009). Investment Tribunals and Human Rights: Divergent Paths. En P. M. DuPUY et al. (ed.), Human rights in international investment law and arbitration. Oxford University Press.

HowARD, D. M. (2017). Creating consistency through a world investment court. Fordham Int'l $L J, 41,1-52$.

Kaufmann-Kohler G. y Potestà M. (2020). The Interplay Between Investor-State Arbitration and Domestic Courts in the Existing IIA Framework. En Investor-State Dispute Settlement and National Courts. European Yearbook of International Economic Law. Springer, Cham.

Kelsen, H. (1928). La Garantie juridictionnelle de la constitution: la justice constitutionnelle. Impr. Barnéoud. Marcel Giard.

Kingsbury, B. y Schill, S. W. (2010). Public Law Concepts to Balance Investors' Rights with State Regulatory Actions in the Public Interest-the Concept of Proportionality. En S. W. SCHILL (ed.), International investment law and comparative public law. Oxford University Press. LANGFORD, M., BEHN, D. y FAUCHALD, O. (2018). Backlash and State Strategies in International Investment Law. En T. AalberTS y T. Gammeltoft-Hansen (eds.), The Changing Practices of International Law (pp. 70-102). Cambridge University Press.

MoeHLECKE, C. (2020). The Chilling Effect of International Investment Disputes: Limited Challenges to State Sovereignty. International Studies Quarterly, 64(1), 1-12.

NinO, C. S. (1997). La constitución de la democracia deliberativa. Barcelona: Gedisa.

Olivet, C., Müller, B. y Ghiotto, L. (2019). ISDS in numbers: Impacts of investment arbitration against Latin America and the Caribbean. Transnational Institute: Amsterdam.

Olivet, C. y Müller, B (2020). Haciendo malabares. América Latina entre la crisis de la pandemia y el arbitraje de inversiones. En CIAR Global. https://ciarglobal.com/informe-haciendomalabares-america-latina-entre-la-crisis-de-la-pandemia-y-el-arbitraje-de-inversiones/

Penades, M. y Tent, P. (2019). Enforcement of Arbitration Agreements by National Courts: What Level of Review? En FACH GÓmeZ, K. y LÓPEZ, A. M. (eds.). 60 Years of the New York Convention Key Issues and Future Challenges, Kluwer Law International B.V.

Prieto, G. (2017). Ecuador's 2017 Termination of Treaties: How Not to Exit the International Investment Regime. Braz. J. Int'l L., 14, 178-191. 
Prieto, G. (2018). El lus Constitutionale Commune frente al derecho internacional de inversiones. Desafíos en la construcción de principios comunes. Max Planck Institute for Comparative Public Law \& International Law (MPIL) Research Paper, (2018-14).

PRIETO, G (2018). El precedente en el derecho internacional de inversiones: el valor argumentativo de decisiones arbitrales previas. Iuris Dictio, 22, 89-99.

Prieto, G. (2019). The Colombian Constitutional Court Judgment C-252/19: A new frontier for reform in international investment law. EJIL Talk! Blog of the European Journal of International Law. https://www.ejiltalk.org/the-colombian-constitutional-court-judgment-c-252-19-anew-frontier-for-reform-in-international-investment-law/

Prieto-Ríos, E. y UREÑA, R. Glencore contra Colombia: una condena agridulce. Razón Pública. https://razonpublica.com/glencore-contra-colombia-una-condena-agridulce/

REINISCH, A. (2008). The role of precedent in ICSID arbitration. Austrian Arbitration Yearbook, 495.

ROA, E. (2001). Tratados internacionales y control previo de constitucionalidad: una propuesta para evitar que la impartición de justicia sea motivo de responsabilidad internacional para el Estado mexicano. En VAladÉs, D. y GutiÉRreZ, R. (coords.). Justicia. Memoria del IV Congreso Nacional de Derecho Constitucional, I, 175-207.

ROA, J. (2019). Control de constitucionalidad deliberativo. El ciudadano ante la justicia constitucional, la acción pública de inconstitucionalidad y la legitimidad democrática del control judicial al legislador. Universidad Externado de Colombia.

SChreuer, C. (2005). Calvo's Grandchildren: The Return of Local Remedies in Investment Arbitration. The Law \& Practice of International Courts and Tribunals, 4(1), 1-17.

SCHILL, S. W. (ed.) (2010). International investment law and comparative public law. Oxford University Press.

SCHILL, S. W. (2017). The Constitutional Frontiers of International Economic Law. EJIL Talk! Blog of the European Journal of International Law. https://www.ejiltalk.org/the-constitutionalfrontiers-of-international-economic-law/

SCHultz, T. y DuPONT, C. (2014). Investment arbitration: promoting the rule of law or overempowering investors? A quantitative empirical study. European Journal of International Law, 25(4), 1147-1168.

Serrano, A. y Gutiérrez, D. Latin America moving fast to ensure water services during COVID-19. En The Water Blog. World Bank Blogs. https://bit.ly/2TuiQ13

SHANY, Y. (2005). Toward a general margin of appreciation doctrine in international law? European Journal of International Law, 16(5), 907-940.

Simma, B. (2011). Foreign Investment arbitration: a place for human rights? International \& Comparative Law Quarterly, 60(3), 573-596.

SORnARAJAH, M. (2016). An International Investment Court: panacea or purgatory? Columbia FDI Perspectives. Perspectives on topical foreign direct investment issues (180). https://bit.ly/3ngklAB

Suciu, D. C. (2019). Los arbitrajes de energías renovables contra España a la luz de la sentencia del Tribunal de Justicia de la Unión Europea en el asunto Achmea. Revista Electrónica de Estudios Internacionales (REEI), (37), 1-27. 
Sweet, A. y Cananea, G. (2014). Proportionality, general principles of law, and investor-state arbitration: response to José Álvarez. New York University Journal of International Law and Politics, 46(3), 911-954.

TienhaARA, K. (2018). Regulatory chill in a warming world: The threat to climate policy posed by investor-state dispute settlement. Transnational Environmental Law, 7(2), 229-250.

TITI, C. (2016). The European Union's Proposal for an International Investment Court: Significance, Innovations and Challenges Ahead. Transnational Dispute Management, 1. https://bit.ly/371Cl74

TITI, C. (2020). Control constitucional y derecho internacional de inversiones a través de cuatro sentencias constitucionales en Colombia, Ecuador y la Unión Europea. Revista Latinoamericana de Derecho Internacional, número especial (en proceso de publicación).

URueÑA, R. (2018). Después de la fragmentación: ICCAL, derechos humanos y arbitraje de inversiones. Max Planck Institute for Comparative Public Law \& International Law (MPIL) Research Paper (2018-30).

Urueña, R., \& Prada-Uribe, M. A. (2019). Constitucionalismo transformador y arbitraje de inversión: elementos para un estándar de revisión constitucional nacional estricto. Max Planck Institute for Comparative Public Law \& International Law (MPIL), Research Paper (2019-05).

VADI, V. (2015). The migration of constitutional ideas to regional and international economic law: The case of proportionality. Nortbwestern Journal of International Law \& Business, 35(3), 557-590.

VAN DEN BerG, A. J. (2007). New York convention of 1958: Refusals of enforcement. ICC International Court of Arbitration Bulletin, 18(2), 1-35.

VAN HARTEN, G. y LOUGHLin, M. (2006). Investment treaty arbitration as a species of global administrative law. European Journal of International Law, 17(1), 121-150.

VAN HARTEN, G. (2007). Investment treaty arbitration and public law. Oxford University Press.

VAN HARTEN, G. (2008). A case for an international investment court. In Society of International Economic Law (SIEL), Inaugural Conference. https://bit.ly/3gMyaEx

VAn HARTEN, G. y MALYSHEUSKI, P. (2016). Who has benefited financially from investment treaty arbitration? An evaluation of the size and wealth of claimants. An Evaluation of the Size and Wealth of Claimants (January 11, 2016). Osgoode Legal Studies Research Paper (14).

VOn BogDAndy, A. y VenZKE, I. (2013). On the functions of international courts: An appraisal in light of their burgeoning public authority. Leiden Journal of International Law, 26(1), 49-72.

Von Bogdandy, A., Casal, J. M. y Morales Antoniazzi, M. (2020). La resistencia del Estado democrático de derecho en América Latina frente a la pandemia de covid-19. Un enfoque desde el ius commune. Max Planck Institute for Comparative Public Law \& International Law (MPIL) Researcb Paper (2020-35), 1-92.

ZARRA, G. (2017). Right to regulate, margin of appreciation and proportionality: Current status in investment arbitration in light of Philip Morris v. Uruguay. Brazilian Journal of International Law, 14(2), 95-121. 


\section{Listado de documentos}

BVerfG. (2016). Judgment of the First Senate of 06 December 2016-1 BvR 2821/11. http:// www.bverfg.de/e/rs20161206_1bvr282111en.html

CIADI. (2020). Informe Anual sobre las actividades del Centro Internacional de Arreglo de Diferencias Relativas a Inversiones. https://bit.ly/3kAuAOP

Columbia Center on Sustainable Investment. (2020). Call for ISDS Moratorium During COVID-19 Crisis and Response. http://ccsi.columbia.edu/2020/05/05/isds-moratorium-during-covid-19/

Corporate Europe Observatory. (2020). Cashing in on the pandemic: bow lawyers are preparing to sue states over COVID-19 response measures. https://bit.ly/31Oe5HL

International Institute for Sustainable Development. (2017). Best Practices Series: Exbaustion of Local Remedies in International Investment Law. https://bit.ly/2 HHaJyI

UNCTAD. (2014). Investor-State Dispute Settlement. UNCTAD Series on Issues in International Investment Agreements II. https://unctad.org/system/files/official-document/diaeia2013d2_en.pdf

UNCTAD. (2020a). Informe sobre las inversiones en el mundo. La producción internacional después de la pandemia. UNCTAD/WIR/2020. https://unctad.org/webflyer/world-investment-report-2020

UnCTAD. (2020b). Investment Policy Monitor. Investment Policy Responses to the Covid-19 Pandemic. Special Issue n. ${ }^{\circ} 4$. https://bit.ly/34yjW5C

\section{Laudos arbitrales}

CIADI / Centro Internacional de Arreglo de Diferencias Relativas a Inversiones (2004). SGS Société Générale de Surveillance S. A. c. República de Filipinas. Caso n. ${ }^{\circ}$ ARB/02/6. https://www. italaw.com/cases/1018

CIADI / Centro Internacional de Arreglo de Diferencias Relativas a Inversiones (2004). Corporación y Activos Ponderosa L.P. c. República de Argentina. Caso n. ${ }^{\circ}$ ARB/01/3. https://www. italaw.com/cases/401

CIADI / Centro Internacional de Arreglo de Diferencias Relativas a Inversiones (2005). Decisión sobre objeciones a la jurisdicción. Aguas del Tunari, S. A. c. República de Bolivia. Caso n. ${ }^{\circ}$ ARB/02/3. https://www.italaw.com/cases/57

CIADI / Centro Internacional de Arreglo de Diferencias Relativas a Inversiones (2006). Fraport AG Frankfurt Airport Services Worldwide c. República de Filipinas. Caso n. ${ }^{\circ}$ ARB/03/25. https:// www.italaw.com/cases/456

CIADI / Centro Internacional de Arreglo de Diferencias Relativas a Inversiones (2007). Decisión de jurisdicción. Saipem S.p.A. c. República popular de Bangladesh. Caso n. ${ }^{\circ}$ ARB/05/07. https:// www.italaw.com/cases/951

CIADI / Centro Internacional de Arreglo de Diferencias Relativas a Inversiones (2007). Piero Foresti, Laura de Carli y otros c. la República de Sudáfrica. Caso n. ${ }^{\circ}$ ARB(AF)/07/01. https://www.italaw.com/cases/446 
CIADI / Centro Internacional de Arreglo de Diferencias Relativas a Inversiones (2012). Vattenfall AB c. República Federal de Alemania. Caso n. ${ }^{\circ}$ ARB/12/12. https://www.italaw.com/cases/1654

Corte Permanente de Arbitraje (2012). Pbilip Morris Asia Limited c. Mancomunidad de Australia. Caso UNCITRAL n. ${ }^{\circ}$ 2012-12. https://www.italaw.com/cases/851

CIADI / Centro Internacional de Arreglo de Diferencias Relativas a Inversiones (2016). Laudo del 8 de julio de 2016. Pbilip Morris Brands Sàrl, Pbilip Morris Products S. A. y Abal Hermanos S. A. c. República Oriental de Uruguay. Caso n. ${ }^{\circ}$ ARB/10/7. https://www.italaw.com/cases/460 CIADI / Centro Internacional de Arreglo de Diferencias Relativas a Inversiones (2016). Eco Oro Minerals Corp. c. República de Colombia. Caso n. ${ }^{\circ}$ ARB/16/41. https://www.italaw.com/ cases $/ 6320$

CIADI / Centro Internacional de Arreglo de Diferencias Relativas a Inversiones (2017). Gas Natural v. Colombia, Gas Natural Fenosa Electricidad Colombia S. L. y Gas Natural SDG S. A. c. República de Colombia. Caso n. ${ }^{\circ}$ UNCT/18/1. https://bit.ly/2TAagkP

\section{Jurisprudencia}

Corte Constitucional de Colombia (3 de febrero de 2014). Sentencia T-055/14. Selección de casos por presentar unidad de materia. M. P.: Alberto Rojas Ríos. https://www.corteconstitucional. gov.co/relatoria/2014/t-055-14.htm

Corte Constitucional de Colombia (6 de junio de 2019). Sentencia C-252/119. Control de constitucionalidad del Acuerdo entre el Gobierno de la República de Colombia y el Gobierno de la República Francesa sobre el Fomento y Protección Recíprocos de Inversiones. M. P.: Carlos Bernal Pulido. https://www.corteconstitucional.gov.co/relatoria/2019/c-252-19.htm

Corte Constitucional de Ecuador (10 de agosto de 2020). Dictamen n. ${ }^{\circ}$ 3-20-EE/20A. Dictamen desfavorable sobre la recaudación anticipada de impuestos con motivo del decreto presidencial 1109 y la pandemia del Covid-19. Juez Ponente: Karla Andrade Quevedo. https://www.fedexpor.com/ wp-content/uploads/2020/08/Dictamen-No. 3-20.EE20A.-Corte-Constitucional.pdf

Corte Constitucional de Ecuador (10 de agosto de 2020). Dictamen n. ${ }^{\circ}$ 5-20-EE/20A. Dictamen favorable sobre la recaudación anticipada de impuestos con motivo del decreto presidencial 1137 y la pandemia del Covid-19. Juez Ponente: Hernán Salgado Pesantes. https://bit.ly/3oFVFmj

Corte Constitucional de Ecuador (18 de septiembre de 2020). Dictamen n. ${ }^{\circ}$ 6-20-CP/20. Constitucionalidad de la petición de consulta popular propuesta por el Concejo Municipal de Cuenca, respecto de la probibición de actividades mineras a gran y mediana escala en cinco zonas de recarga bídrica ubicadas en dicho cantón. Juez Ponente: Karla Andrade Quevedo. 